\title{
José Hernández: Un Siglo
}

\section{NOTA BIBLIOGRAFICA A DOS RECIENTES PUBLICACIONES}

Los cien años transcurridos desde la aparición del poema de José Hernández han constituido un siglo de crítica controversial; sin embargo esa misma controversia nos está permitiendo despejar la imagen y estar en condiciones de poder descubrir la verdadera fisonomía del poema hernandiano. $Y$ en un plano más amplio, lo mismo podemos decir hoy de la crítica que se ha tejido en torno a lo que tradicionalmente hemos venido llamando literatura gauchesca o, más precisamente, poesía gauchesca, entedando este concepto, frecuentemente, con los de poesía popular, tradicional y payadoresca. Hoy, las perspectivas críticas se han afinado, han recibido aportes valiosos de otras disciplinas y cuando usamos los conceptos arriba mencionados sabemos exactamente qué campo delimitan. Por eso, este centenario del Martín Fierro lo veo como un instante propicio para detenernos no sólo en un volumen que conmemora tan trascendente aniversario, sino también en otro que nos trae -como aquél- los últimos hallazgos críticos y los textos literatios que informan esa peculiar poesía rioplatense.

Veamos primero el libro acerca del poema objeto de la celebración.

Martín Fierro, un siglo (Buenos Aires: Editorial Xerox Argentina, 1972), 396 pp. + copia xerográfica de la 1ra. edición de El gatucho Martín Fierro (1872) y de La Vueltad de Martín Fierro (1879).

Este homenaje al centenario de la 1ra. edición del poema ha sido hecho con la colaboración de Horacio J. Becco, Ramiro de Casasbellas y Osiris Troiani en el aspecto literario, y de Jorge A. Iaquinandi en la dirección gráfica. Se han tirado 200 ejemplares especiales (numerados de I a CC); 500 ejemplares numerados de 1 a 500; 500 ejemplares numerados de 501 a 1000 que fueron otorgados a UNICEF para su venta con fines humanitarios y 2800 ejemplares sin numerar destinados 
gratuitamente a gobiernos, universidades, centros de enseñanza, bibliotecas públicas e instituciones culturales de la República Argentina y el exterior, todos los cuales constituyen la edición original.

El volumen se integra con la adición, en un bolsillo agregado a la contratapa posterior, de la copia xerográfica de las primeras ediciones de la 1ra. y 2da. partes del poema de José Hernández.

A la presentación hecha por el Presidente de Xerox Argentina, Juan Martín Allende (h.), quien conceptúa el volumen como un verdadero manual del martinfierrista, sigue uñ artículo de José E. Clemente --" $M F$ 72 '- - en el que subraya los valores diversos, eternos y extranacionales del poema y la oportunidad de su exaltación en el agitado año de 1972. Luego de estas palabras liminares comienza el volumen organizado en cuatro cuerpos críticos que suponen otros tantos enfoques posibles del poema. Acerquémonos a cada uno de esos cuerpos.

- Fuentes críticas fundamentales contiene trabajos especialmente redactados para este volumen y en los que se pasa revista a las diferentes posturas críticas con que, a través de estos cien años, se ha ido enjuiciando el poema. Son once puntos de vista diferentes, a veces concomitantes o contradictorios los emitidos por Unamuno, Menéndez Pelayo, Martiniano Leguizamón, Leopoldo Lugones, Ricardo Rojas, Federico de Onís, Eleuterio F. Tiscornia, Carlos A. Leumann, Ezequiel Martínez Estrada, Jorge L. Borges y Angel J. Battistessa. Como se ve, una recorrida desde 1875 hasta la actualidad realizada por críticos que trazan las líneas básicas de esas posiciones, las defienden o refutan, mostrando, en suma, lo que la crítica más reciente ha consolidado, rescatado o desechado en estos cien años de escrutinio ininterrumpido del poema.

Dos son los artículos que discuten la importancia del reconocimiento crítico de Unamuno. Son ellos debidos a Angel J. Battistessa y a Antonio Pagés Larraya. Battistessa ("Unamuno y Menéndez Pelayo. Sus juicios en torno a MF", pp. 21-28) revisa aquí los juicios contemporáneos al poema de Unamuno y Menéndez Pelayo, destacando su primacía frente a una crítica eminentemente periodística y a reacciones epistolares de amigos. Señala Battistessa que no se dispone aún de una compilación ordenada de los trabajos de Unamuno sobre el $M F$, pero que se podrían espigar juicios interesantes sobre el poema y su autor. No obstante, encuentra "algunas viejas proposiciones todavía orientadoras".

Lo que Battistessa destaca como "señalamientos valiosos" de la crítica de Menéndez Pelayo. (Antología de poetas bispanoamericanos, Madrid, 1875), es la importancia capital que da al poema no sólo por su lectura sino por la crítica que suscitó en su momento, en lo que Battistessa ve una refutación a la tan mencionada afirmación de que fue a partit de las 
conferencias de Lugones en el Odeón o de la encuesta de Nosotros, cuando se inicia el reconocimiento definitivo del poema. M. Pelayo, a diferencia de Unamuno, considera que es probable que el poema "no sea tan genuinamente popular" con lo que se adelanta a observaciones de la crítica actual y lo mismo cuando señala que lo social es demasiado visible, especialmente en la $2 \mathrm{da}$. parte, en detrimento de los valores estéticos. Cabría agregar a las observaciones de Battistessa con respecto a la admiración del poema por parte de Unamuno que éste se sintió fuertemente atraído por el clamor vital y el saber desnudo que lo alienta, que es precisamente lo que observa, muy acertadamente, el otro crítico que se ocupa de este mismo tema: Pagés Larraya ("Unamuno y el $M F^{\prime \prime}$, pp. 29-35). Pagés coincide con Battistessa en que el interés de Unamuno por el poema inicia "la valorización moderna de la obra" y cita los textos dispersos que mencionaba Battistessa: por ej., la carta a Arzadum del 3-VIII-1892 y el "Prólogo" a Querellas del ciego a Robliza de L. Maldonado (1894). Lo desgarrador y conflictivo es lo que entusiasma a Unamuno y "con ello - dice Pagés- inaugura una secuela crítica del mismo signo que va desde Ricardo Rojas hasta Ezequiel Martínez Estrada".

Pagés destaca los pioneros aciertos de Unamuno con respecto al carácter social del poema. Unamuno analiza la separación que el sistema capitalista establece entre los dueños de la escritura y los sometidos para quienes esa palabra es de poder mágico, con lo que — sostiene Pagés"Unamuno se adelanta $(. .$.$) a lúcidos análisis actuales, como los de$ Jacques Derrida sobre el carácter abruptamente reaccionario de la escritura". Puntualiza Pagés que la época de estos comentarios unamunianos coincide con un periodo de intensas preocupaciones metafísicas y sociales unamunianas y de adhesión al marxismo, al anti-positivismo y a la filosofia hegeliana.

Otro aspecto de la crítica en que Unamuno fue precursor es.la diferencia que establece entre el momento en que Fierro es quien refiere su propia historia y cuándo es Hernández quien la interpreta desde fuera, con lo que se da una ruptura entre el propósito moral y la fuerza expresiva, afirma Pagés. Unamuno reelabora así "la dialéctica entre significante y significado del $M F(\therefore)$. La 1 ra. cumple una función poética, es voz; la 2a. cumple una función literaria, es escritura", sostiene con categórica exactitud Pagés. Este artículo es de singular interés pues abre nuevas perspectivas críticas de acercamiento al poema.

Félix Weinberg se vuelve hacia un olvidado precursor y propulsor del reconocimiento del $M F$ ("Martiniano Leguizamón y el MF", pp. 37-40) pasando revista a los aportes del incansable y original estudioso de lo 
criollo. Weinberg sostiene que a los trabajos de Leguizamón se debe el procesc de definitiva consagración del poema.

En dos artículos de desigual calidad y carentes de profundidad, infortunadamente, se revisan los aciertos y errores del genial Leopoldo Lugones. Julio Caillet-Bois ("El Payadtor de Leopoldo Lugones", pp. 45-46) destaca que lo que Lugones quería era "ennoblecer el poema vulgar, demostrando su clarísima genealogía épica, que hace remontar hasta Homero y Dante. MF es el poema inicial y decisivo de la nacionalidad argentina, que debe apoyarse en él...". Lo que le parece esencial en el trabajo de Lugones es el hecho de que él vio al gaucho como un "dechado y prototipo moral de la Argentina". El artículo resulta excesivamente breve y lacónico. Por empezar, creo que lo más interesante hubiera sido discutir a fondo el carácter épico que Lugones le asignó con excesiva generosidad. La marginalidad del gaucho y su progenie, sus carencias, sus limitaciones, la historia de sus desdichas: hambre, despojo, sometimiento, desnudez; el latrocinio ejercido por los que detentaban el poder no se asemeja, por modo alguno, al canto de un héroe victorioso, a la majestuosa dignidad de guerreros gloriosos que son los protagonistas paradigmáticos de la epopeya. No hay duda, me parece, del carácter antiépico de estas criaturas gauchas. Son antihéroes que se quejan con acentos elegíacos, a veces, pero más frecuentemente con la frustración del hombre escarnecido $y$ sin esperanza en un contexto social injusto y trágico.

El artículo de León Benarós ("MF y Hernández en El Payador de Lugones", pp. 41-44) exalta a Lugones como uno de los tres hombres que tomó en sus manos la tarea de "levantar la lápida con que la clase social pretendidamente culta. .." intentó enterrar el $M F$, afirmación que ya hemos visto que no es exacta. Destaca, naturalmente, las conferencias del Odeón de 1913 y su posterior reelaboración en El Payador.

Las ideas de Ricardo Rojas sobre el poema hernandiano también están asediadas por dos críticos. El trabajo de Ismael Moya ("MF en el pensamiento de R.R.", pp. 47-50) se limita a los que él considera los aciertos del pensamiento de Rojas: su "relevante obra de investigación", prueba de su "patriotismo lleno de pureza"; el hecho de considerar el poema como una "epopeya de la democracia" colectivo, porque su personaje esencial es el pueblo; el acierto de que sea el Moreno quien cierre la payada; la semejanza que Rojas descubre entre Fierro y Santos Vega dado que ambos se silencian ante contendientes desconocidos y entre La Cautiva y el espíritu hernandiano pues tomó de Echeverría elementos que luego integró en su poema. Por el contrario, el artículo de Bruno C. Jacovella ("R.R. y su concepción equívoca de $M F$ ", pp. 51-56) es po- 
lémico y señala con claridad lo que debemos al afán del ilustre profesor, pero también los errores que sus ideas contribuyeron a difundir. El problema de Rojas - a quien reconoce haber introducido el poema en las aulas universitarias y en los anales de la literatura argentina-, dice Jacovella, fue que, al querer explicar el poema como colectivo, cayó en interpretaciones inconsistentes por la carencia documental propia de su época. Sostiene que hasta los 40, con los descubrimientos de Juan A. Carrizo, nadie sabía qué era la poesía folklórica y qué relación tenía con la gauchesca. Los equívocos de Rojas se justificaban por un naciona. lismo "adverso a la hispanidad e indiferente a la catolicidad...". A Ricardo Rojas, pues, le convenía, dado su pensamiento, presentar el $M F$ como una epopeya colectiva en que el aeda expresaba el sentir de todo un pueblo, con elementos primitivos. Pero sus ideas estaban desarrolladas sobre bases falsas; por ejemplo, no existen cielitos recogidos por tradición oral. Todos están impresos "y son de hechura entre popular y popularizante". Esta poesía, ni en 1810 ni nunca, penetró en la tradición popular. Hernández creó su poema con "soberana indiferencia" respecto de las tradiciones en boga. Lo único que sí usó fue el octosílabo. Su sextina es su "hallazgo individual" y no una estrofa payadoresca, como creyó también Leopoldo Lugones. Por lo tanto, no se puede llamar a Hernández puyador como lo hace Rojas. Su poema fue "fuera de serie". Jacovella lo ve como "un iluminado, el ejecutor de una misión (palabra que usa Ricardo Rojas), así como $M F$ tiene los visos de un milagro" (el subrayado es del autor). $M F$ no es, pues, la culminación de una tradición oral o del géneto gauchesco, sino "el fruto de un carisma recibido en un tramo fundacional o crítico de la nacionalidad". "La intuición de Rojas no era enteramente desacertada, pero quiso probar lo improbable: la existencia de una conexión orgánica entre una tradición popular sin historia y una historia nacional sin tradición". Cabría agregar a estas observaciones de Jacovella que, puesto que lo gauchesco se prolonga con posterioridad al $M F$, lo gauchesco no termina en la literatura argentina con este poema. O sea, que no se lo puede ver en un proceso cerrado en que Hernández hubiera llevado hasta sus últimas consecuencias el desarrollo de la literatura gauchesca.

Olga Fernández Latour de Botas analiza un trabajo crítico cuya importancia ella demuestra de la mejor manera pero que, en general, no es tan recordado como debiera ("Federico de Onís. Vigencia de sus planteos sobre El Martin Fierro", pp. 57-66). Para la folklorista argentina el trabajo de Onís, que data de 1925, es "el más serio y sistemático de los planteos realizados en su tiempo sobre el tema del $M F$ y la problemática de su origen literario o popular, de su creación individual o colectiva". 
Onís, a diferencia de Ricardo Rojas, no ve el $M F$ como poema popular por la formación literaria de Hernández y por las circunstancias individuales en que fue escrito. Divide la poesía gauchesca entre la hecha por autores cultos citadinos que imitan el habla rural - "poesía artística"-- de la que el poema de Hernández es el fin de la serie, y la de los payadores que cantaban o recitaban sus poemas o los de otros pero de los que no hay testimonio escrito. Diferencia, asimismo, el poema de la poesía gauchesca "política" (cielitos) pero, arguye Onís, que si el $M F$ tuviera sólo como antecedente a los poemas gauchescos literarios, sería una obra popular sin antecedentes tradicionales y sin elaboración colectiva. Lo cierto es que existía en la Argentina una poesía popular, de los payadores, de vida propia, y popular que estaba aún viva cuando los poetas cultos escribían sus poemas gauchescos. Aunque en las poesías populares tradicionales no hay nada en lo que Hernández hubiera podido apoyarse, Onís va al Facundo y a Hudson y encuentra una temática similar: la desgracia, el encuentro con la partida, la leva. Rastrea fórmulas de iniciación semejantes a las de Hernández, provenientes del quichua. O sea, como dice la profesora Fernández Latour, "deja sentada (...) la importancia de las piezas narrativas folklóricas argentinas para establecer correctamente la filiación del poema...". Para Onís, el $M F$, con su autor conocido y de genuina esencia popular, venía a reconciliar las dos opuestas teorías decimonónicas: la romántica en la que el pueblo hace la epopeya, y la positivista para la que sólo la creación individual cuenta en el arte. Investigaciones posteriores, especialmente las de Menéndez Pidal, han esclarecido que, si bien hay siempre un creador individual, los grupos populares adoptan aquello que se aviene a sus pautas consuetudinarias, los adoptan y transmiten, tradicionalizándolos así y dando lugar a variantes regionales.

Fernández Latour precisa en su artículo los deslindes que separan la poesía gauchesca de "lenguaje rústico; sobre temas rústicos; de autor letrado y difusión impresa", de la poesía folklótica o folklore poético (de acuerdo con la terminología de Cortázar), poesía en "lengua común y hasta con intención de ser pulida; sobre temas preferentemente 'humanistas', y (..) nunca esencialmente descriptivos de la naturaleza ó el medio circundante: de autor anónimo, o destinado a pasar al anonimato, y difusión oral por medio del canto, aun cuando pueda ser conservada en cuadernos manuscritos". El $M F$ es, no cabe duda, poesía gauchesca pero diferenciada de la anterior porque Hernández se apartó de lo folklórico lo suficiente como para elegir objetivamente lo más característico de ello y hacerlo sentir como folklore ante la cultura urbana y también se apartó de lo gauchesco lo bastante como para no deformarlo y lograr 
un producto lo más semejante a lo auténticamente popular. Esto lo han clarificado los folkloristas científicos, pero lo anunció Onís y lo intuyó Borges.

La investigadora, azuzada su curiosidad, empezó la búsqueda de piezas narrativas extensas en las que Hernández se hubiera podido inspirar. Estudió los derivados criollos del romance español, en cuartetas $a b c b, c o-$ nocidas con los nombres de corrida, corrido, letra, compuesto y argumento, palabra usada por Hernández. Encontró algunos que consideró bistóricos por su tema, plenos de realismo tal como los romances viejos españoles. Otros son imaginativos, relatos mayormente protagonizados por animales antropomorfizados. Otros, por fin, los versos de averia o cantares matonescos, narran las desventuras de hombres que se 'desgracian', son perseguidos por la justicia hasta que el desgraciado muere violentamente o se pierde en el desierto como un nuevo mairtir, apto para su mitificación y 'canonización' por la imaginación popular. Aquí debe de estar la fuente del $M F$, pues Hernández debió conocer estos cantares de matones. Además, la folklorista tiene documentadas las correrías de un gaucho Martín Fierro por Buenos Aires, Entre Ríos y la Banda Oriental entre 1797 y 1802 .

"Tales versiones satisfacen la condición requerida por F. de Onís, de ser piezas narrativas extensas, responden a los modelos esbozados por Sarmiento y Hudson, y no utilizan nunca la convención idiomática, característica de la poesía gauchesca, de origen letrado. (...) Nuestra tesis es que, complementados con las formas líricas, dialogadas y paremiológicas del folklore argentino, esos argumentos criollos deben reemplazar definitivamente, con su existencia histórica ampliamente documentada y con su vigencia en la memoria de algunos hombres, aun en nuestros días, la invención de que entre la poesía tradicional y la poesía gauchesca hubo un eslabón perdido, una "poesía payadoresca", en diálogo gauchesco y sobre temas rústicos, hoy irrecuperable ( ...). Folklore poético y poesía gauchesca son dos campos literarios que se comunican directamente". Este es uno de los artículos más valiosos del libro, cuyo sentido se completará en la 2a. parte con el de A.R. Cortázar, el iniciador de esta aproximación folklórica a la poesía gauchesca.

El considerable aporte de Eleuterio F. Tiscornia a la edición del poema es analizado por dos críticos de indudable solvencia en ese terreno: Angel J. Battistessa y Julio Caillet-Bois ("E.Tiscornia y su edición de $M F$ ", pp. 67-71 y "El $M F$ de Tiscornia", pp. 73-75, respectivamente). Caillet-Bois conceptúa las ediciones de Tiscornia como "una fundamental renovación de los estudios de literatura gauchesca (...), importan una nueva etapa, de carácter estrictamente filológico, que él cumpliría a lo 
largo de 20 años, solo" y Battistessa afirma que la edición de Tiscornia para el Instituto de Filología en 1925 fue "el primer esfuerzo estimable en una presentación anotada del relato". Caillet-Bois subraya que a Tiscornia le debemos la restauración del texto de la 1 ra. parte al que incorporó algunas enmiendas inéditas de Hernández y que puso en manos del público un texto seguro aun con las inconsecuencias gramaticales que algunos habían querido borrar. El haber completado su estudio con el volumen sobre $L a$ lengua de $M F$, continúa Caillet-Bois, ha llevado a comprender que el habla gauchesca no es una "jerga anárquica y plebeya, separada por un abismo de la lengua general". Después de la investigación de Tiscornia, dice Battistessa, "poco queda por hacer en lo que se refiere al texto y a la lengua del relato", pero lo que perturba a Battistessa es que aún se necesita "un estudio que dilucide el uso personal que hizo Hernández de esa modalidad expresiva gauchesca". Battistessa, con su exquisita sensibilidad literaria, ha señalado una perentoria necesidad en la crítica del poema. La lengua del $M F$, la de Hernández, es una pura creación artística, un acto de invención lingüística. En esa lengua hay gauchismos, expresiones rúrales arcaicas o aún en uso hasta en la ciudad, transgresiones a la sintaxis, la morfología, la fonética. No es exactamente 1a lengua bonaerense de 1870. Hernández buscó en la lengua de la campaña que él conocía bien, asimiló esas formas y sobre ellas inventó una lengua que no es menos real que la que él había oído pero que está ensanchada, enriquecida, quebrantada por su voluntad artística. Y esa importancia estética es lo que le confiere valor y la hace vivir. El error de Tiscornia fue querer ver en esa lengua una especie particular frente a una suerte de gauchesco ideal, naturalmente inexistente. De todos modos, para realizar el estudio que Battistessa propone, la investigación de Tiscornia será muy útil, como el mismo Battistessa lo reconoce.

El próximo estudio está dedicado a los afanes martinfierristas de C. A. Leumann y es Angel Mazzei quien se acerca a "La obra crítica de Leumann" (pp. 77-80) para destacar los tres ramales de esa obra: el de la edición crítica, el de El poetat creador, y el de La literatura gaucbesca y la poesía gaucha. Mazzei subraya el valor de la reconstrucción del proceso de elaboración del poema a partir del manuscrito de la 2a. parte, la depuración de las corrupciones y de algunos falsos problemas textuales, la determinación de la puntuación y la fijación del sentido. de los octosílabos de la payada.

$\mathrm{La}$ ingente obra de Martínez Estrada es auscultada por Dardo Cúneo ("El $M F$ de Martínez Estrada", pp. 81-85) y Frida S. de Mantovani ("E1 $M F$ de Martínez Estrada", pp. 87-90). Cúneo no ve sino el negativismo de Martínez Estrada. Simplifica en exceso sus ideas y no es justo con la 
inmensa tarea de penetrar en la obra, en el protagonista, en su mundo, en la vida argentina que esos dos volúmenes de Muerte y transfiguración de Martín Fierro significan. En cambio, la Sra. de Mantovani asevera que "Descubrir la belleza de la fea verdad (...) es lo que se propuso Ezequiel Martínez Estrada en su $M y T$ (...). Es que siempre sospechó de las apariencias y por eso supo escoger los puntos sensibles, es decir, los mitos intocables, sin importarle que se le viniera encima toda la guardia del templo". Esto es exacto y es con esta perspectiva que hay que juzgar $M y T$. Ella reconoce, además, que por todo lo que abarca, más parece obra de equipo que de un solo autor. La Sra. de Mantovani percibe bien los objetivos de Martinez Estrada: el rechazo del mito del gaucho como dechado de virtudes argentinas; la destrucción del autoengaño; el revisionismo de lo nacional argentino. Al mismo tiempo ella denuncia el mito que se ha forjado alrededor de Martínez Estrada como "destructor de ídolos". No lo fue, sólo que jamás se dejó trabucar por fachadas más o menos relumbronas. $Y$ haber señalado todo esto es lo que ella considera el gran mérito de Martínez Estrada. Haber enseñado, además, agregaría, a hacer una lectura significativa, actual, relevante del poema en el contexto total de la formación de la nación argentina.

Horacio J. Becco en "El $M F$ de Jorge L. Borges" (pp. 91-96) discute cómo el tema gauchesco está enraizado en Borges y cómo hay en él una genuina tendencia hacia "la comprénsión abarcadora de la poesía gauchesca, y en forma especial, sobre la obra de José Hernández"' A pesar de que no se le ocultan a Becco ciertas repeticiones de conceptos en los distintos trabajos borgeanos, reconoce que siempre hay "un mismo esquema constructivo", y que si bien el MF de Borges carece de valor crítico es una recreación que comprueba sus recursos de escritor y de estilo.

Becco analiza comprehensivamente la tesis borgeana sobre lo gauchesco. Indudablemente, como Becco lo reconoce, el juicio de Borges es más personal que analítico y su libro "una serie de variaciones sobre la literatura gauchesca". Uno de los errores fundamentales de Borges fue unir la sextina hernandiana a formas estróficas payadorescas, sin comprender - como Becco lo señala aquí y lo desarrollará más adelante en un artículo-, que esa estrofa fue de la total invención de Hernández. También discute Becco el que Borges rotule el poema como novela. Creo que más exacto sería decir, dada la pobreza anecdótica del poema, que él contiene ciertos elementos novelescos, to que es natural porque se dan humanas situaciones conflictivas pero esto no significa que sea lícito llamarlo novela en su totalidad.

Por último, en esta parte, Juan C. Ghiano analiza "Los estudios de Battistessa". (pp. 97-101). Se trata de valorizar el capítulo sobre "José 
Hernández" que Battistessa redactó para la Historia de la literatura argentina de R. A. Arrieta y su edición de las dos partes del poema. Ghiano destaca, con sobria admiración y con justicia, un rasgo característico de toda la obra crítica de Battistessa: la estrictez metodológica que conforma su investigación. Ghiano observa agudamente la "erudición cernida" y la "comprensión penetrante" con que Battistessa ilumina su estudio, el tono polémico que muy pocas veces lo abandona y lo personal y original de su análisis. Destaca aciertos que la crítica posterior ha confirmado: el ver la lengua del gaucho como "una modalidad del habla rural argentina, con base en el español popular y arcaizante" trasmutada en creación literaria por la imaginación del poeta; el proponer la designación de poesia a la manera gauchesca en vez de la de Rojas, poesia gauchesca; el reconocer los primeros aportes críticos de Unamuno, Menéndez Pelayo, Onís, Lugones, Leguizamón, Rojas, Tiscornia y Leumann los mismos a quienes este volumen consagra articulos especiales; la puntualización de las semejanzas y diferencias entre ambas partes del poema "rutinariamente igualadas por la visión crítica". Igual equilibrio encuentra en la edición crítica, deteniéndose ante una novedad de las notas de Battistessa: "la atención a rasgos estilísticos, olvidados habitualmente por los escoliastas". La frase que cierra el trabajo del profesor Ghiano es otro acierto en la comprensión de la obra de Battistessa: "La lección de los estudios de Battistessa insiste en una actitud que ha fundamentado sus muchos y decisivos análisis de autores nacionales y europeos: el poeta en su poema".

- Revisión de la vida y obra bernandiana. Dos artículos se ocupan de problemas referentes a la biografía y a su deslizamiento en la obra. Son ellos el de Ramiro de Casasbellas y el de R. A. Borello.

"Los biógrafos de Hernández" (pp. 131-137) del primero de los nombrados, es un interesante, útil e inteligente articulo que recorre brevemente las biografías escritas, considerando la más aceptable la de Noé Jitrik ya que es "un intento certero, el más desapasionado e ingenuo, por describir algo que es esencial en el hombre y en el poeta Hernández: su curva política, desde el anti-urquicismo de 1853-54 al liberalismo que lo exalta en la década del 80". No obstante, Casasbellas señala que ninguno de los biógrafos de Hernández, ni los más recientes, han aclarado 6 momentos de la vida de Hernández: 1) ¿Cuándo su abuelo lo envía al lado del padre: 1843, 1844 ó 1846 ?; 2) ¿Qué actividades lleva a cabo Hernández después de la batalla de El Tala?; 3) ¿Cuándo emigra a Paraná: a principios de marzo de 1858 , en marzo o en julio de ese año, como parece más seguro, en 1855?; 4) ¿Qué pasa con Hernández entre 
1864 y 1867 ?; 5) El próximo enigma corresponde a 1868 , cuando Hernández forma parte del gobierno de Evaristo López y 6) Tampoco se sabe la fecha exacta de su partida a Montevideo, ¿1873 ó 1874? En todos estos casos, Casasbellas aduce las diferentes opiniones de los distintos biógrafos y cuál es la que más probablemente se acerca a la verdad por estar mejor documentada o sacar mejor provecho de nueva documentación. Iguales oscuridades puntualiza el autor en cuanto a las ideas y militancia política de Hernández para terminar con la mayor laguna de toda la biografía hernandiana: "¿cuándo surgió en él la idea del MF?", con lo que demuestra fehacientemente que, a pesar de lo mucho escrito, aún hay investigaciones productivas por emprender.

Rodolfo A. Borello en "La simultaneidad de lo biográfico y lo social en la voz de $M F$ " (pp. 117-122) da un primer paso en el análisis de un aspecto no estudiado del poema: "la forma en que Hernández va intro. duciendo lo social y ejemplar, lo genérico-histórico; en el destino personal, en la voz autobiográfica y tristísima del protagonista". Dos líneas simultáneas no contradictorias de significaciones: "la de un destino individual (=una autobiografía) que, a la vez, es ejemplar y génerica (=una clase social) (...). Fórmulas coloquiales indirectas, el uso del impersonal (o despersonalizador) $s e$, las formas reflexivas, la apelación a los indefinidos uno, el gaucho, el hombre, las referencias retóricas al público son algunos de los instrumentos estilísticos por los cuales Hernández crea en el lector esa extraña y múltiple sensación de que el hombreFierro es muchos hombres (...). Y una cuidada alternancia de referencias biográficas y de relatos y de observaciones genéricas, dejan este precipitado complejo que ha hecho de su existencia un paradigma social e histórico". Buen aporte a un tema que, en efecto, necesita una cuidada investigación.

Angel H. Azeves, "José Hernández, periodista" (pp. 105-108) pasa revista a los periódicos en que colaboró, dirigió o poseyó destacando dos rasgos: su patriótica preocupación por el progreso y unidad de la Repú. blica y la existencia de una cantidad de artículos que se le atribuyen sin certeza y que exigen un análisis estilístico que despeje las dudas. Es lás. tima que Azeves no haya creído oportuno of recer por lo menos un texto y realizar una primera tentativa exploratoria. De todos modos, la mera indicación de que esta tarea está aún por realizarse es útil pues apunta otra de las carencias de la bibliografía hernandiana.

León Benarós dirige su atención a "Los ilustradores de $M F$ " (pp. 113-116) proporcionando: una suscinta pero inteligente evaluación a la vez que una clasificación en dos grupos principales: los que han hecho las ilustraciones con un criterio artístico, esencialmente creativo y los que 
se atienen a un objetivo documental. Entre los primeros nombra a $\mathrm{Ba}$ saldúa, Castagnino, Güiraldes, Páez, Berni, Svanascini, etc. Entre los que adoptan el criterio documental y realista, Benarós destaca, acertadamente, al primer ilustrador del poema, Carlos Clérici, subrayando la circunstancia, no destacada hasta ahora, de que en 1880 - un año después de La vuelta-Clérici ilustró el Juan Moreira de Gutiérrez. Dice que esta "contemporaneidad, por lo menos artística (...) merece estudio", lo cual es exacto. Cita, además, entre los que documentan, a Saubidet, Zavattaro, Marenco y Lamela. (Véase la ilustración de Marenco en la página 56.)

Emilio Carilla vuelve una vez más sobre "Los prólogos dél $M F$ " (pp. 123-130).1 Es útil en este volumen clarificar, como lo hace Carilla, el valor de los prólogos de J. Hernández a su libro único. Porque prueban, sin lugar a dudas, que Hernández redactó su poema de manera consciente. $Y$ es también útil establecer claramente que esos prólogos son tres: la carta-prólogo a Miguens que aparece al frente de la 1ra. parte en 1872; la carta de Hernández a los editores de la 8a. edición (Montevideo, 1874) y las "Cuatro palabras de conversación con los lectores" que acompañan La vuelta en 1879. Queda bien especificado que la cartaprólogo "revela las intenciones de Hernández y hasta sus motivos de jactancia"; que la carta en la edición de 1874 es una "reiteración y ampliación" de los conceptos de la carta anterior más ciertas particulares declaraciones de Hernández acerca de los fines de su poema "centrados en torno a un solo aspecto: la situación del gaucho y la sociedad argentina". En el prólogo a La vuelta, si bien Carilla observa otra vez amplia. ción y reiteraciones de lo mismo, subraya también un aspecto no tocado en los prólogos anteriores: el de que el libro pretende "despertar la inteligencia y el amor a la lectura en una población casi primitiva, a servir de provechoso recreo, después de fatigosas tareas, a millares de personas que jamás han leido". Carilla atribuye inteligentemente este cambio de enfoque a que Hernández quería mostrar su reconocimiento por los lectores del campo que habian determinado el éxito del poema. Además, observa con precisión que al acentuarse las intenciones didácticas de Hernández se debilita su afán de defensa del gaucho lo cual está de acuerdo con el mayor volumen que las sentencias moralizantes adquieren en esa 2da. parte. Pero aún descubre Carilla otro rasgo no observado antes en este prólogo y es el "ambicioso paralelo con la riqueza paremiológica de otros pueblos", conceptos que llevan a Carilla a sos-

1 "Sobre lós prólogos del MF", NRFH, XIII, 3-4 (1959), 339-345 recogido luego en Estudios de literatura argentina (Siglo XIX) (Tucumán: Universidad Nacional, 1965), 81-89 y reelaborado y ampliado en La creación del MF (Madrid: Gredos, 1973), pp. 24-38. 
pechar ciertas lecturas por parte de Hernández, sospecha confirmada en dos casos por el mismo Hernández: en un caso se trata del prólogo de Vicente F. López al libro de José Ma. Ramos Mejía La neurosis de los bombres célebres en la bistoria argentina (1878) en que hay observaciones semejantes a las hechas por Hernández. La otra referencia de Hernández es al libro La sabiduría popular de todas las naciones. Nadie hasta Carilla, había completado esta referencia. Su autor es Ferdinand Denis y su autor y difundidor en América, el curioso Vicente Pazos Kanki. También, en su sabiduría refranera, Hernández acusa la lectura de otros libros franceses de la época, como los de Quitard y Duplessis. Esta rica búsqueda bibliográfica ilustra en profundidad y sugiere mucho acerca de los intereses intelectuales del hombre Hernández.

Fermin Chávez también teitera una preocupación suya anterior relativa a "Los primeros hernandistas" (pp. 155-158). ${ }^{2}$ Es ésta una inteligente y cálida reivindicación de la primacía de algunos contemporáneos de Hernández en la justa valoración del poema contra la opinión repetida - sin verdadera investigación- de que, a la aparición del poema, nadie reparó en él o en su autor. Chávez, bien documentado, empieza por la referencia a la conocida semblanza de Hernández que, en 1870, aparece en el libro de Lucio V. Mansilla; continúa con la dedicatoria que Lussich hizo de su poema a Hernández y con la amistad, anterior al poema, con José Z. Miguens. Da una extensa y minuciosa lista de los comentarios y juicios suscitados por el poema desde el del uruguayo Juan Ma. Torres en 1874 hasta el extenso artículo de Pablo Della Costa en el diario porteño Sudamérica, dos años después de la muerte de Hernández. Es interesante que Chávez considera al potosino Pablo Subieta, quien escribió cinco artículos sobre el $M F$ (1881), "el primer gran crítico del poema y el primer extranjero que lo comenta" y "quien principia el estudio del $M F$ según el enfoque político-social que otros debían replantear veinte años después". Muestra claramente cómo ese interés por Hernández y su poema se continúa durante las décadas del 80 y 90 y termina su artículo con la cita de la carta de Nicolás Avellaneda a Florencio Madero (1881), en que aquél revela conocer muy bien las lecturas de Hernández, lo que es de valor particularmente para los que se interesan por el elemento paremiológico del poema pues Avellaneda afirma algo sumamente curioso y no siempre tenido en cuenta: "...he de pedirle [al Dr. Larsen] que estudie los diálogos de $M F$ y que despojando los dichos de sus expresiones locales los restituya a sus verdaderos

2 "Los primeros hernandistas: Pablo della Costa". En Palabra Hernandista (Buenos Aires), 1 (en.-mar. 1973), pp. 7-17; incluye el trabajo de della Costa, MF. El poeta y el hombre. 
autores, es decir, al Corán, al Antiguo Testamento, al Evangeiio, a Confucio o a Epitecto. Estos dos ulttimos son, sobre todo, los autores predi. lectos de $M F$ y sus dichatachos gauchos no vienen a ser en el fondo sino proverbios chinos o griegos" (el subrayado es mío). No sé si se ha comprobado esta aseveración de Avellaneda. La carta de Avellaneda prueba, por otra parte, que el epistolario a que dio lugat la publicación del poema es de primera validez - y no sólo desde una posición historicista-para reconstruir el clima intelectual en que se recibió la creación hernandiana y la verdadera repercusión que tuvo entre los escritores consagrados $y$, en general, en el ambiente culto porteño. Viene en apoyo de estas observaciones, precisamente, el innovador articulo de un alerta estudioso de Hernández y su poema: Antonio Pagés Larraya, quien aplica su ob. servación a "Las primeras cartas sobre $M F$ " (pp. 175-181). Como todo lo que debemos a la pluma de Pagés Larraya, éste es un artículo sesudo, bien documentado pero sobre todo sensible al valor crítico expresado en el epistolario contemporáneo a la aparición de las dos partes del $M F$. $Y$ que hay que actualizar porque muchos de los aspectos alli discutidos se mantienen aún vivos y hasta, sin exageración, todavía no han sido llevados a sus últimas consecuencias. Son juicios comprometidos por posiciones políticas $y / 0$ estéticas diversas, pero constituyen el primer momento de la crítica al poema, un cimiento del cual hay que partir. Pagés reconoce que Ernesto Quesada, Luis C. Pinto y Ricardo Rodríguez Molas advirtieron el interés crítico del epistolario pero no subrayaron suficientemente el valor precursor de algunas o el hecho de que documentan el clima que iba surgiendo en torno a la obra. Así, por ejemplo, las cartas de BArtolomé Mitre puntualizaron un aspecto que le tocaría a Martinez Estrada desarrollar ampliamente: el del pesimismo del poema; también a Mitre se debe la serie Hidalgo-Ascasubi-del Campo-Hernández que luego se generalizaría y cómo el General supo ver el mismo "cantar opinando" en Hidalgo y Hemández. Subraya, Pagés Larraya, asimismo, la gran diferencia de posturas estéticas de estos dos hombres (igualmente enemigos en lo político): Mitre quiere elevar "la inteligencia vulgat" al nivel del lenguaje poético mientras que Hernández lleva a cabo la sintesis propuesta por Esteban Echeverría: identificar el espíritu del personaje americano con su habla y hacer de ello creación poética.

Sobre la carta de Miguel. Cané lo que resulta más interesante es cómo este escritor comprendió la creación poética del habla del gaucho obtenida por Hernández y cómo, por primera vez, y sin conocer a Hernández, establece una síntesis entre su vida, su mensaje y el público. La carta de Mariano Peliza, citada siempre por haber advertido la dimensión social del poema, le interesa en cambio a Pagés porque Pellizạ 
supo percibir "la oportuna elección de la estrofa", esto es, del sexteto octosilabo, como intencionadamente inventada por Hernández con lo que "la imitación de los trovos campesinos es perfecta". Las dos cartas de JUAN MA. TORRES traen la original - para entonces- aproximación de MF a la novela y su cercanía con los simples relatos de Fenimore Cooper, excepto que "no precisa la zona de mayor aproximación entre Cooper y Hernández — dice Pagés-: ambos rehuyen el tema sentimental y el tratamiento subjetivizado de la naturaleza, dos rasgos unánimes de los novelistas y poetas románticos del Nuevo Mundo". La carta de JuANA MANUEla Gorriti prueba el éxito del libro en Lima y algunas dificultades de lectura, y la de D. Ricardo Palma "menciona tangencialmente a Antonio de Trueba, cuyo posible influjo sobre Hernández convendría explorar - dice Pagés-, por la difusión que en esa época alcanzó el autor español". La carta de José T. Guido trae finas observaciones sobre la tristeza del gaucho que él ve como influjo del paisaje, del desierto, de su aislamiento. Por último, la carta de Adolfo SALdías explora "con sutileza poética, el significado de ese sur que en el poema no se nombra, pero que aun asi alcanza un raro significante".

Pagés ha mostrado fehacientemente que la crítica actual tiene que volver su mirada a estos primeros testimonios para encontrar allí los que muchos reputan como descubrimientos críticos modernos.

Juan C. Ghiano en su artículo " $M F$ en la literatura argentina" (pp. 159-166) hace un excelente sumario que fija, en correcta perspectiva, el lugar de la literatura gauchesca en el marco de las letras argentinas y, dentro de esa literatura, la situación del poema hernandiano. Ghiano parte de El amor de la estanciera, pasa por Maziel, Godoy, Hidalgo, Pérez, Ascasubi y del Campo para desembocar en J. H. y su MF. Hernández, sostiene Ghiano, testimonia y denuncia, pero va más allá pues de los gauchos se pasa a los pobres todos $\mathrm{y}$, aún más, "en La vuelta de $M F$, la protesta se alza en nombre de la libertad esencial del hombre". O sea, que el $M F$ es sí un documento histórico, mas, a la vez, "se impone y perdura por las invatiantes humanas que concreta su mensaje último, firme en el paso del alegato al poema". Entre las perduraciones del género gauchesco en el siglo Xx, Ghiano cita tan sólo la novela de Benito Lynch, El romance de un gaucho, quizá por ser la única escrita - como el $M F$ - desde dentro del gaucho. Un sugestivo pensamiento cierra el artículo y es que la constancia de las formas gauchescas en la Argentina y el Uruguay puede explicarse por razones históricas y literarias. No había culturas indígenas, no existían mitos locales coloniales. El gaucho era la realidad popular más cercana con posibilidades de con. vertirse en representación de lo nacional. 
Roberto F. Giusti, "Complejidad de la creación literaria" (pp. 167170) es reseña al libro de Angel $H$. Azeves. La elaboración literaria del $M F$ que, en la nota a pie de página aparece sin año y que fue publicada en 1960. Saluda en ella el veterano Giusti el que sea una crítica seria, honesta, documentada y perceptiva. Este artículo es reproducción de la reseña que el profesor Giusti publicó en el diario La Prensa de Buenos Aires el 16-VII-1961 y es por ello que aparece en algunas de sus apreciaciones (por ej., la aceptación -aunque cauta-- de las reminiscencias homéricas que Azeves señala en el poema y la casi validación de la calificación lugoniana de epopeya), un poco anticuada.

Ma. Inés Cárdenas de Monner Sans, " $M F$ en la University of Texas Library" (pp. 171-174)..$^{3}$ Es éste un artículo que interesa especialmente al bibliófilo pues en él se pasa minuciosa revista a la colección de ediciones del $M F$ atesoradas en The Latin American Collection de la Biblioteca de la Universidad de Texas en Austin. Es importante destacar que allí están la colección Lucuix y la Martínez Reales de ediciones del poema más la famosa Colección Tinker. La Sra. Monner Sans ha confrontado las ediciones vistas en Texas con los asientos de la bibliografía sobre José Hernández, MF y su crítica. Aportes para una bibliografía que publicó Augusto R. Cortázar en 1960 para el BAAL. Llega a la conclusión de que en Texas hay 67 ediciones que no aparecen en BAAL, cosa que en nada desmerece el trabajo riguroso y pionero de Cortázar dado que, como la misma autora reconoce, habiendo sido el MF el primer bestseller sudamericano, las ediciones clandestinas abundaron.

Raúl H. Castagnino, con su conocido interés por el arte dramático, dirige su atención a "MF y el teatro gauchesco" (pp. 139-147) para darnos un muy buen artículo que trata un tema soslayado por la crítica. Las conclusiones a las que llega Castagnino son las siguientes: que la traslación de una obra de un género literario a otro implica casi siempre la pérdida de la mayoría de sus principales virtudes $y$, pocas veces, "la adquisición de valores que espontáneamente corresponden a la nueva estructura". El $M F$ "por el asunto desarrollado, por el tratamiento elegido para el mismo por Hernández, incuba (...) la tendencia hacia el epos". De modo que los riesgos de la adaptación teatral eran considerables. Castagnino considera que los intentos de teatralización del poema se debieron a tres razones bien justificadas: en primer lugar, los elementos dramáticos latentes en toda la literatura gauchesca: intercambio de noticias entre personajes populares; sátiras, críticas irónicas, quejas frente

3 Este artículo fue el publicado en Cuadernos del Sur. (Bahia Blanca, Universidad Nacional del Sur), 8-9 (jul. 1967-jun. 1968), pp. 161-163. También apareció cn La Prensa (Buenos Aires) el 17-IX-1967. 
a ciertas condiciones socio-políticas, la conexión de personajes reales o imaginarios por el relato o el diálogo que pueden ser fácilmente corporizados. En segundo lugar, "la circunstancia de haber nacido en el picadero circense el teatro gauchesco mediante la dramatización de un relato y la necesidad de nutrir un repertorio obediente a la misma tónica social". En última instancia "el hecho de que un dramaturgo consagrado hallara en las protestas y alegatos del gaucho M.F. (...), coincidencias con la personal militancia ideológica". Explica que con las dos primeras razones puede uno acercarse a la versión del uruguayo Dr. Elías Regules, $h$, - que Castagnino discute en detalle- y que no llegó nunca a eclipsar la permanente difusión del poema y que tampoco obtuvo el éxito y popularidad del Juan Moreira escénico. La tercera razón tiene que ver con la versión realizada por el avezado dramaturgo José González Castillo. Es un momento de profesionalización incipiente, de búsqueda de nuevos horizontes. "Con criterio de hombre de teatro, González Castillo desmembra la estructura original del poema y la rearma para la operatividad escénica. En la concepción hernandiana, Fierro es actante e informante a la vez. En la estructura teatral propuesta (...) es sólo actante y pasan a la condición de informantes personajes anónimos del poema, en cuyos labios se actualizan los textos informativos originales". Termina con este juicio: "La versión de González Castillo aprovecha todos los personajes de primer plano del poema: Fierro, Cruz, el hijo menor de Fierro, el moreno payador; opaca al hijo mayor, minimiza a Vizcacha, ignora a Picardía. Da, en cambio, mayor intervención dramática a una serie de segundones: juez, alcalde, pulpero, napolitano, inglés, etc.; todos ellos apenas nombrados, en forma general, en el poema. Al cambiar de género la obra original debió resignar numerosos elementos estructurales que no funcionan del mismo modo en el relato que en el escenario. La habilidad del adaptador superó en casi todos los casos ese obstáculo. Sin embargo, el que fundamentalmente se nota ausente es un elemento no declarado en el poema, aunque de latente presencia $(\ldots)$ : la sugestión de la rueda de oyentes $(.$.$) ; consiguientemente, se ha esfumado el trasfondo pa-$ yadoresco del poema. El canto, convertido en acción actual, pierde la envoltura evocativa; se objetiviza y agosta su atmósfera subjetiva y sugestiva". Agreguemos que una nueva versión del poema hecha por el profesor Ghiano el año pasado y que fue presentada tres días en el Teatro Nacional Cervantes, recibió una fría acogida por parte de la crítica. Este interesante y minucioso estudio de Castagnino cubre las principales preguntas que pueda hacerse un interesado en el tema y abre la puerta para un similar trabajo que pudiera hacerse sobre la versión cinematográfica de Torre Nilsson. 
Augusto Raúl Cortázar retorna en el "MF en su centenario" a la "Interpretación y perspectivas a la luz de la investigación folklórica" (pp. 149-154) cuyo abanderado él ha sido. Este texto es una reelaboración y condensación del artículo "MF a la luz de la ciencia folklórica; fundamentos teóricos y propuestas de mi investigación" destinado a la revista Logos.* Las conclusiones que entrega son por demás iluminadoras y no se podrá prescindir de ellas para acercarse al poema hernandiano. Parte de lo que ya ha explicitado en sus trabajos anteriores, a saber, que hay una diferencia entre el folklore poético del gaucbo y la poesía ganchesca que es 'proyección' de aquél y traza el siguiente itinerario de un proceso de folklorización que va desde la "prehistoria del $M F$ " (los "poemas matonescos" del artículo ya comentado de la profesora Botas) hasta los frutos contemporáneos: conocimiento por los grupos folk debido a la trasmisión oral del poema desde el lector al auditorio, o por el canto y la recitación; selección intuitiva de algunos pasajes por el auditorio; repetición y memorización; variantes propias de esta trasmisión, primero sincrónica y luego diacrónica con lo que se inicia la tradicionalización; asimilación de esos fragmentos con la funcionalidad propia de los fenómenos específicamente poéticos; regionalización y, finalmente, el fruto folklorizado contemporáneo. A los ejs. que había aducido en sus obras anteriores, agrega aquí Cortázar, con la probidad que lo caracteriza, los aportes de nueva documentación de campo, debidos a sus alumnos de la carrera de Antropología en la Facultad de Filosofía y Letras de la Universidad de Buenos Aires. Ellos confirman la hipótesis de que en la actualidad se está cumpliendo una etapa en el proceso de folklorización fragmentaria del $M F$ que así "surge como un egregio monumento entre dos corrientes. (...) capta la corriente de un pasado remoto, la asimila, la reelabora, la recrea y la transfiere a la posteridad, dándole su propia voz, su tono, su ESTILO. Por otra parte, hay una corriente que mana del poema, convertido en germen del folklore argentino, documentada en cantares criollos iletrados de varias regiones de la patria. Se está produciendo una trasmutación, de carácter popular y anónimo, es decir, folklórico". Esta seria y documentada trayectoria es el mejor homenaje que puede rendirse al poema de Hernández. Porque no se trata de la muerte y transfiguración mítica del pobre gaucho solitario, sino de su consustanciación con sus hermanos de sangre en su propio suelo.

Horacio J. Becco se ocupa de uno de los problemas más apasionantes

* Acabado de pasar a máquina este trabajo he recibido la separata del trabajo anunciado: "MF a la luz de la ciencia folklórica. (Fundamentos teóricos y propuestas de investigación)", Logos, No. 12 (1972), pp. 5.20. 
que el poema hernandiano ha despertado: el de "La sexteta de $M F$ " (pp. 109-112) y construye un estudio por demás valioso que agrega algunos datos interesantes al siempre debatido tema. Becco afirma rotundamente, como Martínez Estrada, la patente de invención de Hernández para esta forma estrófica. Lo que cabe, pues, preguntarse es de dónde la sacó. Lugones y Borges se la atribuyen a Lussich pero Becco (al igual que Battistessa antes) desbarata esa afirmación con la simple compulsa de los textos: $M F$ es seis meses posterior a Los tres gaucbos orientales, pero es claro que el $M F$ no es obra que pudo escribirse a vuela pluma en tan corto tiempo y por un hombre siempre tan ocupado como Hernández. Que Lussich le hubiera leído su poema, Becco cree que es probable pero eso lo único que prueba es la mayor estatura poética del argentino. La novedad que ahora pone Becco a nuestra disposición, son las últimas indagaciones practicadas por J. A. Carrizo: él sospechaba que Hernández, durante su exilio en la ciudad brasileña de Sta. Ana do Livramento pudo oír la sexteta octosilábica común en el folklore brasi eño en boca de los gaúchos cantores de Río Grande do Sul. En las compilaciones brasileñas, las sextetas responden a la fórmula $a b c b d b$, esto es, se trata de una sexteta romanceada, con rima en los versos impares blancos, mientras que la sexteta de Hernández es de disposición abbccb o abbcbc. Carrizo no pudo hallar la forma folklórica de la sexteta pero "descubrió, en cambio, un antecedente curioso de los consejos; (...) en el poeta de la Escuela de Minas, Ignacio Alvarenga Peixoto (1744-93), cuyos Conselhos a meus filbos..." compreden doce estrofas de fórmula abbaba, "la misma de $M F$, pero sin el primer verso blanco". Hay semejanzas formales y estilisticas con el brasileño de modo que pudo existir, si no una imitación, un influjo de los Conselbos de Peixoto. La hipótesis no resulta, pues, totalmente caprichosa. Este artículo de Becco creo que pone punto final al problema de la sexteta (o sextina o sextilla) hernandiana no sólo en cuanto a que fue de la exclusiva invención de Hernández, sino también en cuanto a que su innovación tenía bases en una realidad cercana que él pudo conocer y que su privilegiado oído captó como el molde más apropiado en que vaciar su canto gauchesco.

- Apéndice documental. En esta parte del volumen se aducen los documentos a los que se ha hecho referencia especialmente en la .2a. parte y, casi estaría tentada de decir, que este apéndice debiera ser leído no aparte sino en especial conjunción con estos artículos: el de Pagés sobre las cartas; el de Chávez sobre los primeros hernandistas; el de Casasbellas sobre los biógrafos de Hernández; y el de Carilla sobre los prólogos, pues aquí aparecen la mayor parte de los documentos aludidos. El material 
está agrupado de la siguiente manera: "Juicios críticos sobre $M F$ (18731880)": epistolario (pp. 185-194); "Martín Fierro": los cinco artículos de Subieta (pp. 195-203); "El gaucho MF. La vuelta de MF poemas camperos por J. H.": dos artículos: uno del diatio La América del Sur del 9-III-1879 y otro de La Biblioteca Popular de Buenos Aires dirigida por Navarro Viola; " $M F^{\prime}$ ': un artículo sin firma de La Capital del Rosario del 11:X-1878 y las dos cartas de Juan Ma. Torres publicadas en el periódico La Patria de Lima. Notamos esta discrepancia: Pagés al estudiar las cartas, afirma que ambas fueron fechadas en Montevideo el 18 y 23II-1874 pero aquí la segunda carta aparece fechada en 1873. "Bibliografia": carta de Mariano Pelliza, la reseña publicada en El Mercantil de Buenos Aires el 6-II-1873 (en el asiento 689 de la Bibliografía de Becco se da como fecha el 5-II-) firmada con el seudónimo "Lautaro" y un editorial de La Tribuna de Montevideo del 23-III-1873 sin firma que fue luego reproducido por La Patria de Lima junto con algunos fragmentos del poema. "José Hernández (Autor del Gaucho MF)" contiene un artículo sin firma y sin fecha de El Mercurio de Rosario que apareció después en La Tribuna (Montevideo) con fecha 13-XII-1873. "MF" es la poesía homónima del libro de José Ma: Zubiría El peregrino del Plata (1875) y que parece, por la nota que la acompaña, haber sido publicada en un periódico. "Cartas poéticas al poeta colombiano Jorge Isaacs" por Salvador Mario contiene "Carta última" con la que envía un ejemplar del poema al ilustre novelista. " $M F$. Críticas injustas. Estética y filosofía" trae la entusiasta defensa del poema hecho por el Dr. Moorne', una especie de "carta abierta" de este Profesor del Colegio Nacional y que apareció incorparada a la 13a. edición del poema (Buenos Aires: Libreria $M F, 1894$, pp. LVIII-LX) y reaparecerá nuevamente en la 14 a. edición, tres años más tarde. Es una entusiasta defensa para que no se niegue al $M F$ cabida en los programas de enseñanza. Aparece seguidamente el texto de la "Carta a los editores de la 8a. edición" por J. H. escrita en Montevideo en 1874 y estudiada por Carilla. "J. H. (18341886)" es la conocida biografía escrita por el hermano Rafael. Cierra el Apéndice la "Bibliografía de MF. La 11a. edición de la 1ra. parte" reseña de Bartolomé J. Ronco publicada inicialmente en El Tiempo (Azul, provincia de Buenos Aires) el 30-VII-1939 y que importa por la idea que la guía y que su análisis prueba y es el de que el establecimiento de "un texto definitivo y exacto de la 1 ra. parte de $M F$ no debe buscarse en una determinada edición, de las doce que forman la serie [publicadas antes de la muerte de Hernández y con su conocimiento]. sino en la comparación minuciosa de todas ellas". Es lástima que en esta 
sección no se haya consignado la primera crítica al poema. Me refiero a la aparecida en el periódico La Pampa el 17-I-1873 y que es de interés no sólo por ser la $1 \mathrm{ra}$. reacción sino por algunos puntos que fueron relevantes en su momento y todavía lo son ahora: el valor de 'moralidad' que se vio en el poema y el objetivo del poema que era hacer sentir los ecos de la poesía en la vida de los hombres de campo.

- Bibliografía bemandiana (pp. 263-396). Esta última parte del singular volumen que reseñamos es quizá la más valiosa y la que resultará de consulta obligada, a partir de este año, para todo el que se aboque al estudio serio del $M F$. Su autor, Horacio J. Becco es uno de los bibliógrafos argentinos más serios y uno de los que conocen más a fondo la literatura gauchesca. Lo comprobaremos al comentar su nueva Antología por si no bastaran las muchas publicaciones que en ese campo ha hecho. Esta Bibliografía es el resultado de numerosos años de paciente y exacta labor. En su "Introducción" Becco recorre los "Antecedentes bibliográficos" existentes sobre J. H. y su obra y cita los hasta ahora fundamentales: 1) Itinerario bibliográfico y bemerográfico del $M F$ de José $C$. Maubé (1943); 2) A. R. Cortázar, J. H., MF y su crítica. Aporte para una bibliografía (1960), con 583 asientos; 3) H. J. Becco, J.H. y M.F. en Cuadernos del Idioma (Buenos Aires) en los Nos. de jul. y oct. de 1966 con 716 asientos y 4) D. W. Foster y V. R. Foster, J. H. en Research Guide to Argentine Literature (New Jersey: The Scarecrow Press, 1970). De modo que esta Bibliografía que Becco entrega ahora, con sus 1050 asientos a los que sumados unas 170 notas complementarias a ciertos asientos, elevan el total a 1220 , es la más comprehensiva que se ha publicado hasta el presente sobre Hernández y su poema. Dado que Becco envió a la imprenta este material en julio de 1971, todo el material publicado durante el año 72 será recopilado en una próxima bibliografía, en la que aparecerán también algunas ediciones cuyos ejemplares no han podido ser compulsados directamente por Becco.

La Bibliografía está metódicamente organizada de la manera que se explica a continuación y referencias cruzadas simplifican grandemente su manejo y reducen el tiempo de la búsqueda. Comprende las siguientes secciones:

I-Ediciones: a) El gaucbo M.F. ; b) La vuelta de $M F$; c) $M P$ (unificación de las dos partes bajo este nombre a partir de 1910); d) Ediciones sin fecha; e) Ediciones sin editor ni fecha.

Las primeras ediciones aparecen ordenadas cronológica- 
mente pero separando las de La Ida (15) y las de La vuella (10). Se da una detallada descripción de ellas y, en notas complementarias, sus variantes, gruesos errores y toda clase de cambios. Se consignan también las ediciones fraudulentas o clandestinas.

II - Ediciones facsimilares.

III -- Traducciones (alemán, árabe, armenio, catalán, checo, esloveno, 'francés, griego, guaraní, hebreo, húngaro, inglés, italiano, lituano, rumano, ruso, sueco).

IV - Otras obras de J.H.: a) Libros; b) Periódicos y artículos; c) Epistolario; d) Antologías. No se tocan las ediciones de las Obras completas "que deberá tentarse sin demora" y que hubiera alargado y complicado este trabajo. Aunque no es exhaustiva, la seción $\mathrm{b}$ ) es la de mayor número de asientos. $\mathrm{Y}$ lo mismo puede decirse de la c) que constituye un inicio que, con seguridad será ampliado en lo sucesivo, empujado por estudios como los del Dr. Pagés.

V-Critica: a) Biografía y homenajes; b) En la literatura gauchesca; c) Su obra. Critica general.

Aquí se toma la personalidad del poeta y escritor y la división establecida resulta difícil de aceptar como rigurosa pues, como el mismo Becco lo reconoce, un mismo artículo unifica varios temas. Becco ha preferido correr un riesgo antes que estrechar más los grupos propuestos o ser aún más restringido en las subdivisiones. Sólo la compulsa frecuente nos permitirá decir qué es lo que hubiera resultado más útil para el usuario.

VI - El poema $M F$; a) Crítica sobre el poema; b) Personajes; c) Lingüística; d) Aspectos sociales y políticos; e) Relaciones literarias; f) Teatralización.

Esta parte, naturalmente, es la más considerable de la bibliografía.

VII - Miscelánea de publicaciones no fundamentales sino complementarias como un artículo sobre una exposición plástica del poema, un No. de Caras y Caretas dedicado al gaucho, diversas revistas $M F$, etc.

VIII - Bibliografías.**

\footnotetext{
* Hubiera sido interesante que Becco hubiera creído oportuno reproducit las secciones "Discografía" y "Filmografia" que apatecieron como novedad en su Bibliografía de Cuadernos del Idioma.
} 
La sección "Bibliotecas consultadas" da idea del amplio radio abarcado por Becco pues a las infaltables Biblioteca Nacional de Buenos Aires y la de la Academia Argentina de Letras, se suman la del Congreso de la Nación, la del Museo José Hernández, la del Museo Mitre, la del Museo de Motivos Populares José Hernández y la del Jockey Club en Buenos Aires a más de las fundamentales de los Estados Unidos: la de la Organización de los Estados Americanos, la del Congreso, la New York Public Library y la de la Universidad de Texas en Austin. El volumen se cierra con un índice alfabético de nombres de utilidad obvia.

En suma, que con esta Bibliografía Becco consigue su propósito de proporcionar si no un registro absolutamente total de lo producido sobre J. H. y su obra (lo cual no creo que sea posible a menos que se tratara de un equipo y que se trabajara en diversas partes de la Argentina y del resto del mundo), sí una selección crítica singularmente fundamental, orientadora y abarcadora de todos los enfoques hechos hasta el presente tanto de J. H. -el hombre- como de su obra.

Se reproducen una serie de ilustraciones pertenecientes a distintas ediciones hechas por artistas de la categoría de Juan C. Castagnino, Héctor Basaldúa, Alberto Güiraldes, Carlos Alonso, Juan A. Cotta, Eleudore E. Marenco, Roberto Páez y Norberto Onofrio con lo que el volumen, elegantemente encuadernado, of rece un digno encuadre al tema.

No me queda duda alguna de que la afirmación del señor Allende es exacta y de que éste es $e l$ manual del martinfierrista, indispensable para estar al día con respecto a las diferentes (y divergentes a veces) opiniones críticas, para tener una serie de lecturas directrices que luego pueden ampliarse con la ayuda de una bibliografía tan completa y utilísimamente organizada. No empañan la seriedad y utilidad del volumen lo desparejo de algunas contribuciones pero los lineamientos fundamentales de la crítica están allí en su conjunto para quien quiera seguirlos.

Horacio J. Becco, Antología de la poesia gaucbesca. Introducción, notas, vocabulatio y bibliografía de... (Madrid: Aguilar, 1972), 1779 pp.

El volumen se abre con una INTRODUCCIÓN dividida en tres partes con estos contenidos: 1a. Parte: a) "El gaucho": Destaca Becco la falta de investigaciones serias acerca de este tipo social $\mathrm{y}$, en cambio, la abun. dancia de "apología ardorosa" y aun alguna - muy escasa- de vituperio. Y como su tema no es el personaje ecuestre de la pampa sino la poesía gauchesca centrada a su alrededor, Becco, con muy buen criterio, tesume las posiciones adoptadas frente a la personalidad, real o mítica del gaucho, trayendo en su auxilio las cinco categorías críticas establecidas por el sociblogo uruguayo Daniel D. Vidart en su "Prólogo" al libro El gaucbo 
de Fernando O. Assunçao: Ia gauchodoxia, la gauchofilia, la gauchofobia, la gauchosofía y la gauchología."

b) "Vicisitudes de la voz 'gaucho",", en donde se discuten los tres problemas fundamentales: dónde y cuándo empezó a usarse la voz; cuál es su etimología y qué clase de hombre se distinguía con esa designación. La fuente de Becco para responder a estas cuestiones es, fundamentalmente, la obra de Assunçao aunque conoce bien todo lo hecho por otros investigadores. Así quedan al día la primera y la tercera de esas preguntas: que la más antigua referencia al gaucho data de 1771 y proviene de un documento uruguayo. Pero en lo que Becco deja de aportar un dato singularmente importante, es en el problema de la etimología. Porque él acepta las dos hipótesis que Assunço ha elegido, entre las muchas aducidas, como las de mayor responsabilidad: una es la del origen francés -o provenza - de la palabra con extensión de significado; y la otra es la de la transformación guacbo $>$ gducbo por metátesis vocálica. En la "Bibliografía complementaria" Becco da cabida al artículo que proporciona la, hasta ahora, más convincente etimología desde un punto de vista científico. Me refiero a la propuesta por el profesor Marcos A. Morínigo en su artículo "La etimología de gaucbo", en BAAL, XXVIII (1963), 243-250, artículo que se repite, bajo la voz gaucbo, en el Diccionario de Americanismos (Buenos Aires: Muchnik Editores, 1966, 279-283), del que es autor el mismo Morinigo. Evidentemente, este trabajo llegó a manos de Becco demasiado tarde como para discutirlo en esta parte de su libro. Junto a esta carencia quiero, en cambio, señalar, la utilisima lista bibliográfica (de 37 asientos) de las diferentes etimologías y sus fuentes que Becco presenta con agregados a lo ya anotado por Assunçao y recogiendo también lo que traía Arturo Costa Alvarez en El castellano en la Argentina. Quizá la única objeción que pudiera hacerse a esta lista sea la de que hubiera sido preferible una ordenación cronológica de esas etimologías.

c) "Rehabilitación del vocablo galıbo" en que Becco pasa revista a las alternativas de significación - negativa o positiva- que la designación gaucho mereció desde los días de la aparición del tipo humano en el siglo Xvir hasta que "la voz terminó perdiendo su connotación malévola y 'gaucho' se ha convertido vulgarmente en un sinónimo de comedido, servicial, desinteresado y buen amigo". Becco afirma que el tipo humano del gaucho no es privativo de la región bonaerense y que pastores a caballo "tenía que haber a todo lo largo y ancho del territorio argentino y aun de sus países limítrofes". No dejo de reconocer verdad

4 Es de advertir una errata en esta parte del trabajo: en pág. 11, renglón 17, donde dice "gauchofilia" debió decir "gauchofobia". 
en esta afirmación, pero creo, no obstante, que el gaucho de la zona bonaerense y del litoral tuvo un carácter acentuadamente libertario, indó: mito y hasta matonesco por imperativo de la ley de vagancia y por la forma en que se ejercía el comercio de cueros, de que carecieron los campesinos ecuestres de otras regiones del país. $Y$ por ello pienso que hubiera sido útil destacar el concepto emitido por Julio Caillet-Bois de que el tipo gaucho "prospera (...) en la zond de confuisión y choque donde los españoles lucharon con otros pueblos, y especialmente en las dos fronteras próximas con Buenos Aires (..), con los portugueses al N. E. y en la del S. con los indígenas de la pampa...". Se suscribe Becco a la teoría de este crítico en lo que respecta a los tres períodos que comprende la historia del gaucho y diferencia bien que la producción de Hidalgo se refiere a los gauchos de la independencia, la de Ascasubi a los de las luchas entre unitarios y federales, la de Hernández a los de las campañas contra el indio y la de Lussich a los de las refriegas políticas intestinas del Uruguay. Cierra el parágrafo con inteligentes observaciones acerca de la razón para la existencia de una literatura gauchesca cuando un fenómeno similar no se ha dado, por ejemplo, con el llanero venezolano o con el cow boy norteamericano, aunque en este último caso los "westerns" cinematográficos podrían ser considerados como una suerte de literatura del cow boy.

IIa. Parte dedicada a discutir lo que debe entenderse por "La poesía gauchesca". Son páginas de 'puesta al dia' de todas las conclusiones a que la moderna investigación literaria, folklórica, antropológica ha llegado con respecto al tema. Sería alargar innecesariamente esta reseña el comentar cada uno de los parágrafos de la recorrida de Becco, pero quisiera destacar algunos más prominentes. En primer lugar, Becco aporta datos nuevos con respecto a quién usó por vez primera el adjetivo gauchesco "que determina como algo aparte este tipo de poesía" y que no fue término usado "regularmente como adjetivo de gaucho hasta fines del siglo xIx". Se trata de una carta de Estanislao del Campo a Ascasubi del 26-II-1859 en que el autor del Foursto habla de "bajar a la arena de la literatura gauchesca". Luego lo rastrea en las Apreciaciones sobre $M F$ (1874) de Juan Ma. Torres (que aparecen en el volumen comentadio antes). $\mathrm{Y}$ más tarde en una carta de Miguel Cané a Hernández de 1879 (ver "Apéndice documental" de $M F$. Un siglo). ${ }^{6}$ Becco agrega, además, la cronología del uso de garchesco tal como la ha consignado F. Chávez,

5 En Historia de la literatura argentina, dirigida por R. A. Arrieta, T. II (Buenos Aires: Peuser, 1959), p. 59. El subrayado es mío.

${ }^{6}$ pp. 211 y 185, respectivamente. 
para terminar estableciendo que el vocablo ingresó "definitivamente, como categoria didáctica de la literatura rioplatense, en la década de 1890", especialmente después del espaldarazo de Unamuno, M. Pelayo y Rafael Hernández. Todo esto es de destacar porque ninguno de los tratadistas modernos ha advertido esta peculiaridad. Becco subraya inequívocamente que el género gauchesco "pertenece exclusivamente a la poesía" y que dentro de él hay un "subgénero grande y un subgénero chico". Como caracteres generales de esa poesía Becco ve: el mensaje político y un simbolismo social e histórico que ofrece una clave para la interpretación del país (cono ya lo hizo Martínez Estrada); un lenguaje rústico; la personalidad del protagonista que es siempre un gaucho; la naturaleza de la acción que es una lucha de fondo epopéyico ${ }^{7}$ y un escenario particular que es el de la pampa bonaerense. Estas afirmaciones equivalen a una definición del género gauchesco que nunca se había hecho $\tan$ tajantemente. $Y$ lo interesante es la afirmación que sigue y es que esos caracteres sólo los posee por entero el $M F$ y parte de la obra de Ascasubi por lo que llega a la conclusión de que lo que permite incluir a toda esa producción poética en un solo género es la unidad que le confiere la figura del gaucho pero también el octosilabismo y su carácter de poesía dialectal, rasgo que no es privativo de la Argentina y que dentro de este país of rece diversas modalidades y estratos. Para demostrar esto, Becco consigna en una sinopsis los diferentes tipos de poesía en lengua exótica (poesia en babla rural o a la rística, poesía en el babla general sobre temas excéntricos, poesía en lengua regional, poesia en dialecto vulgar, poesía germanesca), utilísima clasificación en un área en que aún hay mucho por investigar. Ligándolo a su afirmación del carácter dialectal de la poesía gauchesca, Becco discute el problema de poesia gaucbesca y tradicional o folklórica y payadoresca resumiendo los trabajos que han aclarado y fijado los conceptos para llegar a la conclusión de que "la poesía dialectal llamada gauchesca, como asimismo la llamada nativista, carecen de antecedentes populares y se explican más bien como una creación, no del pueblo, sino para el pueblo, surgida, no en la campaña, sino en la ciudad". Bajo el subtítulo "Técnica juglaresca y poesía gauchesca" Becco aclara, de una vez por todas, que la poesía gauchesca desde un punto de vista formal y temático, es literatura folkló. rics trayendo en su apoyo la autoridad de las investigaciones de Cortázar, cuyas conclusiones hemos apuntado en el volumen anteriormente reseñado. Aquí se inserta el estudio sobre "La sexteta del $M F$ ", semejante- aunque más minucioso en algunos aspectos- al que comentamos en $M F$. Un

\footnotetext{
7 Antiepopéyico creo que sería más exacto.
} 
siglo. Por último, en esta segunda parte, Becco considera que tan sólo el $M F$ y el Santos Vega de Obligado siguen siendo actuales lo que corrobora la funcionalidad social y cultural del poema hernandiano, acentuada por el proceso de folklorización que señala Cortázar.

IIIa. Parte: "Esquemas biográficos de los poetas incluidos", esquemas sobrios, rápidos pero que contienen todo lo esencial de la vida y la obra de cada autor, rigurosamente puesto al día. Son ellos: Juan B. Maziel, ${ }^{8}$ Bartolomé Hidalgo, Juan Gualberto Godoy, Hilario Ascasubi, Manuel de Araucho, Estanislao del Campo, Antonio D. Lussich, José Hernández, Estẻban Echeverría, Juan María Gutiérrez, Bartolomé Mitre y Rafael Obligado, ${ }^{9}$ nómina que explicita que el criterio adoptado para la edición es el literario de incluir lo de más categoría estética, dentro y fuera de la poesía dialectal, con temas y personajes o rústicos o urbanos, o polémicos o míticos y con metros de cuño o apariencia popular o directamente tradicionales. De ahí que se haga la división en Poesia gauchesca en lengua campera y Poesia gauchesca en lengua generai. Pasando, pues, a los textos mismos debemos decir que la probidad y cuidado que han caracterizado siempre todos los trabajos de Becco, se ven claramente en las fuentes bibliográficas que aduce para cada autor y en el cotejo de ediciones cuyo detalle puede leerse en las pp. 62.63 del volumen. Especifica claramente que muchas de las notas son reproducciones de las de los autores pero que ha agregado aclaraciones complementarias, en particular en lo que se refiere a situar y caracterizar los nombres de personajes históricos (tan necesario en las composiciones políticas de Ascasubi o en los tres poemas de Lussich). Advierte, y con holgada razón, que la extensión de la presente Antología impide una anotación minuciosa y erudita que fatigaría la lectura, desvirtuando, asimismo, opinamos, el propósito inmediato de la colección. Señala también Becco la similaridad de su Antología con la ya clásica de Borges y Bioy Casares del FCE, y reconoce que ha utilizado mucho de su material en las notas lo que, en efecto, es así como lo hemos constatado texto por texto. Por último, aclara que como su recopilación se refiere a un "tejido histórico y crítico en constante elabo-

8 Erróneamente, en la p. 62, Becco al hacer algunas advertencias sobre los textos, dice que parte de Hidalgo, pero de hecho lo hace del romance de Maziel Canta un guaso...

* El orden en que se los presenta es cronológico, por fecha de nacimiento. Sólo en dos casos se altera esta norma: Araucho, nacido en 1803, aparece después de Ascasubi, de 1807. Ello se debe a que Becco toma 1835, la fecha de publicación de Un paso en el Pindaro de Araucho, descartando que una de las poesías gauchescas allí contenidas - Carta de un gaucbo a un proyectista-, apareció en 1828 y es, en rigor, anterior a las primeras poesías en esa vena de Ascasubi que datan de 1833. Más lógica nos parece la ubicación de Lussich, nacido en 1848 , antes de José Hernández del 34 pues la obra de éste es posterior, aunque sólo sea en unos pocos meses, a la del uruguayo como es bien sabido. 
ración" y como la fecha de entrega a la imprenta fue agosto de 1971, seguramente algún "novísimo hallazgo" puede haber escapado a este volumen. Los hallazgos más recientes de que tengo noticias son los de Olga Fernández Latour de Botas y Félix Weinberg, ambos aparecidos en artículos de La Nación, en junio y julio de 1968 , respectivamente. ${ }^{10}$ Esos artículos aportan dos nuevos Diálogos acerca de los cuales, considerada la semejanza de título, estructura, personajes, léxico y estilo, se podría conjeturar que se está en presencia de un nuevo autor gaucbesco ignorado hasta el presente y que habría sido un continuador de lo iniciado por Hidalgo. Acerca del cual, por otra parte, es dable preguntarse (siendo, como parecen esos diálogos de marzo de 1823 y de $1824-25$, respectivamente) si este autor no habría publicado antes otras composiciones gauchescas y, si así fuera, si no serán de su autoría algunas de las composiciones tradicionales atribuidas a Hidalgo y sobre las que existen serias dudas. Sólo un delicado análisis estilístico podrá entregar una respuesta fundada. En la Antología no aparecen composiciones del Padre Castañeda, Sáenz de Cavia, Luis P'érez y algunas anónimas que han sido incluidas en libros últimamente aparecidos tales como el de J. B. Rivera, La primitiva literatura gaucbesca (Buenos Aires: Alvarez, 1968) y el de Fermin Chávez Poesía rioplatense en estilo gaucho (Buenos Aires: Ediciones Culturales Argentinas, 1962) y los de A. R. Cortázar, Poesía gauchesca argentina (ya citado) y Poesia gauchesca (Buenos Aires: Ediciones Culturales Argentinas, 1970). El valor estético de las composiciones allí consignadas es ciertamente menor y creo acertado el no haberlas incluido por cuanto ningún rasgo fundamental agregan a un panorama de lo mejor y más representativo de la poesía gauchesca como es el que esta Antologia proporciona. El lugar de esos otros autores (llamados 'primitivos', 'precursores', 'grupo intermedio' por Cortázar' y Rivera, por oposición a los propiamente gauchescos), es en textos como los antes mencionados, que se detienen en esa investigación y que allí los anotan y comentan con la minucia que su particular objetivo demanda. A menos que se editen todos juntos y en su totalidad bajo el rótulo que usó Rivera para destacatlos. De modo que Becco no ha soslayado nada fundamental, con lo que su Antología va a transformarse en el libro indispensable para todo buen curso de poesía gauchesca (especialmente en este país) ya que todo lo que importa está contenido en él. Es, en verdad, la más completa y mayor antología existente de poesía gauchesca.

10 Olga Fernández Latour de Botas, "Una pieza olvidada de la primitiva poesía gauchesca, en La Nación (2-VI-1968), p. 2; Félix Weinberg, "Un primitivo poeta gauchesco", en La Nación (21-VII-1968), pp. 2 y 4. 
Paso a hacer algunas indicaciones que pueden ser de utilidad para futuras ediciones de este valioso libro.

1) Hubiera sido de desear que cada texto y autor estuvieran identificados en la parte supetior de la página para evitar el tener que recurrir siempre al índice en la búsqueda rápida de un dato, un verso, tal canto de una composición o autor. ${ }^{11}$

2) El texto de Maziel que aparece en Becco sólo lo habíamos visto antes en R. Rojas (Los gaucbescos, t. II, 372) y en el libro de Rivera (op. cit., 63-66), quien se limitó a reproducirlo tal como lo traía Rojas. Becco se mantiene fiel al original. Quizá hubiera debido anotar la voz guaina (buaina). Con muy buen criterio, Becco mantiene la ortografía del original pues mientras algunas palabras llevan $z$ (raz, gazañas, abes. $t r u z$ ) en otras se reproduce el seseo (surrado, disque) y lo mismo ocurre $\operatorname{con} v$ y $b$ y con $b$ o nada.

3) De los textos de Godoy, hasta ahora, no habian aparecido sino algunas composiciones aisladas en Cortázar, ${ }^{12}$ Rivera $^{13}$ y en Chávez. ${ }^{14}$ El libro más exhaustivo escrito hasta el presente sobre el poeta mendocino, el de F. Weinberg, Juan Guaberto Godoy: literatura y politica. Poesia popular y poesia ganchesca (Buenos Aires: Solar-Hachette, 1970), contiene las mismas poesías que trae Becco, excepto que Weinberg ofrece los textos íntegros y no fragmentos como la Antologia que nos ocupa. Pero esto que podría parecer una carencia, está compensado, en el famoso texto del "Corro", con la reproducción de las notas que Dominguito Sarmiento publicó en el Correo del Domingo, No. 37, 4-XI-1864 y que Becco ha tomado del libro de Rodríguez Molas, La primitiva poesía gauchesca anterior a Burtolomé Hidalgo (Buenos Aires: Numen, 1958). Pienso que Becco pudo justificar, en su comentario a Godoy, su inclusión del "Corro" que, en rigor, no es una composición gauchesca y refutar las repetidas afirmaciones de Dominguito acerca de que ese poema inaugura la poesía payadoresca argentina. Ni el lenguaje ni la combinación estrófica son ortodoxamente los de la gauchesca. Pero, excluidas las piezas teatrales primitivas, es evidente que el mérito del "Corro" es haber iniciado la serie de los "diálogos" poéticos no dramáticos, esto es, que Godoy precedió en cinco meses la nueva etapa que abriría Hidalgo. Ahora que,

11 M. Alonso en su Ciencia del lenguaje y arte del estilo, 7a. ed. (Madrid: Aguilar, 1966, pp. 534-535) aconseja: "Si existen varios autores en las páginas pares se escribirá el nombre del autor y en las impares el título correspondiente". 12 En Poesía Argentina Gaucbesca (ed., cit.), trae Cortázar "Al toro (pp. 151-152) y "Cielito" (pp. 153-154) y en Podsía Gauchesca (ed. cit.), "Espinela"; coincidente, pues, con Becco sólo en el "Cielito".

13 Op. cit., pp. 130-138 consigna "Al toro".

14 F. Chávez, Poesía rioplatense enn estilo gauchesco (Buenos Aires: Ediciones Culturales Argentinas, 1962), trae el "Cielito". 
mientras Godoy se mantuvo dentro de la forma de estirpe española, Hidalgo sacó de ella un género nuevo. Como el libro de Weinberg aparece citado en la "Bibliografía complementaria", Becco no debe de haber cotejado su texto con el de Weinberg que éste publicó en base al folleto con el poema hallado en 1963 en la Biblioteca Nacional de Río de Janeiro y que él considera como indudablemente publicado en la imprenta de la Gaceta de Mendoza hacia agosto de 1820. Hay dos diferencias entre ambos textos: v. 53 su parecería errata por un (Weinberg), más lógico; v. 44 Becco: "pudiendo con más juntas asomarse"; Weinberg: "pudiendo con las gentes asociarse". La "Carta" está tomada del texto aducido por Draghi Lucero, Cancionero popular cuyano (Mendoza: Best Hnos., 1938), 85-112. Aquí el cotejo entre el texto de Becco y el de Weinberg - quien también ha manejado el original aparecido en El Corazero de Mendozamuestra algunas diferencias:

$\begin{array}{ll}\text { Becco: } & \text { Weinberg: } \\ \text { v. } 1, \text { desde } & \text { dende } \\ \text { v. } 12, \text { maestro } & \text { mestro } \\ \text { v. } 16, \text { maestro } & \text { mestro } \\ \text { v. } 16, \text { enviarla } & \text { inviarle } \\ \text { v. } 41, \text { quiero } & \text { quero } \\ \text { v. } 49, \text { los } & \text { les } \\ \text { v. } 51, \text { basuras } & \text { basura } \\ \text { v. } 54, \text { veriamos } & \text { variamos } \\ \text { v. } 74, \text { los } & \text { lo } \\ \text { v. } 75, \text { y toditas } & \text { y en toditas } \\ \text { v. } 97, \text { se han trajinao } & \text { se han tragicao } \\ \text { v. } 110, \text { cuando } & \text { como } \\ \text { v. } 114, \text { el } & \text { al } \\ \text { v. } 143, \text { boliando } & \text { volten }\end{array}$

En todos los casos el texto de Weinberg tiene mejor sentido. Para el "Cielito" cotejé el texto de Becco con los de Cortázar y Weinberg. Cortázar es el único que acentúa correctamente óirla (v. 28); las diferencias notadas son las siguientes:

\section{Becro:}

v. 16 , les

v. 20 , del

v. 24 , Estanislao

\section{Cortázar:}

le

de

Estanislao
Weinberg:

le

de

Estanislado 

v. 26 , un
un
el
v. 31 , habría
hará
habrá
v. 44, Esta es conmigo
Esta es conmigo
Esta no es conmigo
(evidentemente $\sin$ sentido).

4) En el Santos Vega de Ascasubi, Becco consigna las palabras que Ascasubi puso al frente de su libro, pero no la "Dedicatoria" a D. Jorge Atucha que hubiera sido útil pues muestra el estado de ánimo del poeta y el valor que la redacción del poema, en ese momento de su vida, tuvo para él como así también los objetivos que con él perseguía.

5) Es lástima que en las composiciones en prosa de Aniceto el Gallo, Becco no haya numerado los renglones porque indudablemente se facilitaría la utilización escolar del texto. La disposición tipográfica de títulos y subtítulos es más acertada que la de la edición de Borges y Bioy Casares. Hay algunas notas de Becco sumamente valiosas como las relativas a ¡cuándo! (v. 48, p. 816) como interjección de duda; la indicación de los cancioneros en que se encuentra el cantar popular No. 14 de Aniceto el Gallo ( $p$. 895); la indicación de las primeras ediciones del diálogo "Contreras recibiendo a Chano" (p. 943), del "Cielito Gauchi-Patriótico" (p. 959), de "Urquiza en la patria nueva" (p. 1012), de "Los compuestos de Gualeguaichú" (p. 1034), del "Cielito patriótico" (p. 1041) - la especificación del primitivo nombre y lugar de publicación de los "Rasgos biográficos de D. Juan Manuel de Rosas" (p. 964) y del episodio de Camila O'Gorman (p. 990). También agrega valiosos ejemplos a la nota de Ascasubi sobre lomo (v. 52, p. 961).

6) En el único otro Iugar en que hemos visto textos de Araucho es en el libro, ya citado, de Rivera ("Diálogo de dos gauchos" y "Décima"). Chávez, op. cit., trae solamente el "Diálogo", mientras que Becco aporta el "Diálogo" y la famosa "Carta al proyectista". Becco ha utilizado el trabajo de L. Ayestarán, La primitiva poesía gaucbesca en el Uruguay, pero parece no haber visto la única edición de las poesías de Araucho, Un paso en el Pindo (Montevideo, 1835). Es evidente, asimismo, que no pudo ver lo que aparece en Rivera. En la "Carta" creo que debió haber explicado mamanchos y está boquiando. No aparecen en el "Vocabulario". Comparando el texto del "Diálogo" en Becco y Rivera, el primero resulta mucho más cuidado en cuanto a puntuación, signos de interrogación, entrecomillado, guiones, etc. Hay una sola diferencia importante: Becco: vv. 89-90 (p. 1073), "para hacerte vomitar / en cuatro suertes de cuajo!"; Rivera: "para hacerte vomitar / en cuatro suertes el cuajo". Aparte las diferencias gramaticales, hay una diferencia de matiz signifi- 
cativo que parece más adecuada en el texto de Rivera. ¿Qué traía el original? Se podrían haber explicado los siguientes giros en el "Vocabulario" o en notas: bijo de angulo; le saco el guano; saliéndome de la vaina.

7) De Estanislao del Campo Becco trae, además del Fausto, las mismas poesías de Anastasio el Pollo que aparecen en la edición de Borges y Bioy Casares y, por cierto también el "Gobierno Gaucho". Es extraño, sin embargo, que Becco no haya sentido la necesidad de agregar la "Carta de Anastasio el Pollo sobre el beneficio de la Sra. de La Grúa" (que aparece en Poesía ganchesca argentina de Cortázar, pp. 217-219), dada la cantidad de crítica que se ha hecho con respecto a la génesis del Fausto y cómo esta poesía de "La Grúa", verdadero antecedente del poema más conocido y festejado de del Campo, echa luz sobre la incógnita, a más de permitir apreciar la mayor sofisticación del poeta cuando acometió su obra mayor. Becco agrega algunos nombres nuevos a la bibliografía sobre el overo rosao (p. 1079) y en las notas en que coincide con Tiscornia sus observaciones son más ceñidas y las referencias modernas.

8) De Lussich Becco aporta los tres textos tradicionales: "Los tres gauchos orientales", "El matrero Luciano Santos" y "Cantalicio Quirós y Miterio Castro en el Club Uruguay". Al final, Becco recomienda confrontar con la edición de Eneida Sansone de Martínez (Montevideo: Biblioteca Artigas, 1964) que reputa como la edición más depurada. Dado que Becco se basó en la edición de Falçao Espalter de 1937 realizamos la confrontación aconsejada con la edición de la Sra. de Martínez y de ella resultan las siguientes diferencias:

"Los tres gauchos orientales"

Becco:

Martínez:

$\begin{array}{ll}\text { v. } 72 \text {, cuajada e } & \text { cuajada de } \\ \text { v. } 79, \text { darles } & \text { darlos } \\ \text { v. } 600, \text { la } & \text { le } \\ \text { v. } 662 \text {, se } & \text { me } \\ \text { v. } 704, \text { blanco } & \text { banco } \\ \text { v. } 968 \text {, calentito } & \text { calientito } \\ \text { v. } 1056 \text {, engaño } & \text { engañó } \\ \text { v. } 1071 \text {, el } & \text { al } \\ \text { v. } 1169 \text {, ese } & \text { este } \\ \text { v. } 2048 \text {, pegao como cojinillo } & \text { si es como coịinillo } \\ \text { v. } 2158 \text {, esté } & \text { usté }\end{array}$


"El matrero Luciano Santos"
v. 98 , el genio
v. 123 , de
v. 206, al
v. 365 , ese
v. 583 , cuantas
v. 916 , también
v. 963 , compincie
v. 1271, lo
v. 1288 , trastabillar
v. 1438 , un
v. 1541, que es pura cencia
v. 2020, y él es trucha
v. 2307, atajas
v. 2422 , del que sólo
v. 2547 , hojas
v. 2567 , Sigún yo supe
v. 2570 , güielta
v. 2573 , a la hembra
v. 2613, manipulaba
v. 2910, ¡No hay cuidao!
v. $3010, \mathrm{mi}$ amigo viejo
v. 3290 , antes hizo alarde
v. 4066, estar penando
v. 4155 , como presumo
en genio
$\mathrm{da}$
el
este
cuántas
cambié
compinche
los
acurrucar
en
de gran cencia
y él que es trucha
atajan
que usté sólo
lonjas
Según yo avirigüé
güella
la hembra
manejaba
¡cuidao!
amigo viejo
vino haciendo
estar maniatando
yo que presumo

\section{"Cantalicio Quirós"}
v. 296 , ese
v. 1065, ¡Qué embromar
v. 1299 , pa egolletarlo
esa
¿Pucha
como pa esgolletar

(Consideramos como erratas del texto de Becco: tarjä (p. 1205), llegasg (p. 1239), coronas por caronas (p. 1244), fez por fea (p. 1251), mi por ni (p. 1261), gaucbo por guacho (p. 1263), fresura por frescura (p. 1263), vida por vido (p. 1271), digo por diga (p. 1273), volorao por colorao (p. 1282), unavez por una vez (p. 1333). 
La edición que la Sra. de Martínez tuvo a la vista es la de Barreiro y Ramos (Montevideo, 1883) que el mismo Barreiro llama la 4a. ed., a solicitud de Lussich y que éste corrigió y aumentó, por lo que se la considera superior a las tres anteriores. No entiendo por qué Becco califica esta edición de la Sra. de Martínez de "depurada" (y lo pone en nota evidentemente agregada, ya que lleva asterisco) puesto que en algunos de aquellos versos en que difieren ( $L 3 G$ : v. 2048, $L S$ : vv. 1288, 2567, 2910, 4066; $C Q$ : vv. 1065 y 1299) la versión de Becco parecería la original pues, métricamente, es más ajustada. Si la edición de F. Espalter traía estas variantes, Becco debió consignarlas para saber de dónde emanan. Los aportes de la edición de Becco son las aclaraciones a algunos modismos (v. 80 ; v. 317 ; v. 398; v. 415), el relacionar una expresión gauchesca a una peninsular semejante (v. 298); la señalización de giros semejantes en otros gauchescos (v. 105; v. 757; v. 882; v. 942, etc.) o en la poesía popular (v. 3429); el aporte de nuevos datos bibliográficos. Consideramos que podría haber anotado los siguientes giros: llevar bacienda para la manga; dentrar a la carpeta; alpiste; yagüané, sumaco, es pierna; paz que jiede a manchas; ser laucba para el menudo; guampa; déle guascal al pereré; irse derechito al guacbo; solfiaos; jastial.

9) Con respecto al texto del $M F$, entre las ediciones que Becco señala que ha cotejado se nota la falta de la de Battistessa (Buenos Aires, Peuser, 1958). Sin embargo, en nota de la p. 1524 se hace evidente que la tuvo a la vista. Becco antecede La ida con "El payador" del poema Celiar de Magariños Cervantes y con la carta a Miguens. Esto nos parece lo lógico pero, infortunadamente, Becco como la mayor parte de los editores del poema hernandiano, hasta los más cuidadosos como él, nos escamotea algo que vemos en la edición del folleto de 1872: la porción del discurso de Nicasio Oroño sobre el problema de las levas y el desamparo del gaucho y un fragmento de un artículo de $L_{\curvearrowleft} N$ ación del 14-XI1872. El primero particulariza el clima histórico, social y político y la situación imperante en la campaña argentina en la época y subraya, inditectamente, la intención con que Hernández escribió su poema. El segundo, aparte de que viene en apoyo de la tesis de que el folleto no circuló sino a principios de 1873, hace hincapié precisamente en los dos rasgos que son más resaltantes en cuanto al gaucho del poema: su perenne hambre y desnudez. Son, pues, dos fragmentos conceptualmente valiosos que hubiera valido la pena difundir.

Becco ha consignado las hileras de puntos suspensivos, esto es, la forma gráfica de la pausa con que en el original se indicaba al lector el cambio del hablante poético. Muchas ediciones las omiten cercenando así uno de los elementos de estilo más significativos, como también lo son 
ciertas mayúsculas o guiones, etc., todos los cuales Becco ha respetado. Para La ida Becco, en los casos de variantes, se atiene ya sea a la edición de 1872 o a la de 1878 , siguiendo - por lo general- las elecciones de Leumann (no anota la variante de 1872 o si lo hace consigna: "Otras ediciones"). Se aparta de Leumann en dos casos: v. 1975 y v. 2019 en que se atiene al texto de 1872. En La vuelta Becco se aparta de la edición de 1879 en los casos en que lo ha hecho Leumann (vv. 304, 306, 1692, 2517,3515 y 3846). Se podrían haber explicado las siguientes expresiones: partido, apretarse el bonete, indijusto, sentar $l_{a}$ de la boca, asariar, candilato, solteriar, culandrera, acomodo, bolazo, liberatos, como un'bendito, ${ }^{15}$ el hacer su papelón, sonar las costillas, cómo se compone el batile, como moro sin señor, porrudo, bacer la tarde, como el cerdo, hacerse bola, enseñarle a comer el grano, ver la luz, Incala-perra, ponerse caliente, desubordinao, medio wivios, irse como lista.

10) Becco ha consignado la "Advertencia" con que Esteban Echeverría encabezó la edición de sus poemas editados bajo el título de Rimas en 1837. Es un texto poco divulgado, ${ }^{16}$ excepto algunos trozos, y es importante conocer su contenido como antesala a La Cautiva, pues constituye una verdadera poética echeverriana.

Becco sigue la 2a. edición de Battistessa que, a su vez, la hizo sobre la 1ra. de las Rimas, pero aquí las notas originales de E. E. aparecen a pie de página y no como en la del eminente crítico argentino, en ei "Apéndice", con lo cual su aprovechamiento se hacía más difícil. No dispongo a mano de la edición de 1837 pero creo que habría que explicar estas diferencias con el texto de Battistessa: en nota a maloca, p. 1584, Becco trae excursión donde Battistessa (y otras ediciones) dice incursión; en C. II, v. 97 les frente a los en Battistessa y otros. En cambio, Becco, como otros editores, trae tema cuando Battistessa copia lema de la nota de E. E. a Antar (p. 1613). Erratas advertidas: C. I, v. 107, p. 1581: balandro por baladro; nota a Valichu, p. 1587, FALKMER por FALKNER pero luego correctamente; en epígrafe a C. VI, p. 1605, MORETó por MORETo. Nos parece que se pudieron explicar grama y pica y que se debió dar la acepción de tordillo empleada en el poema y no sólo la que aparece

$15 \mathrm{La}$ acepción de "bendito" que Becco da en el "Vocabulario" (p. 1689) no es la adećuada para el uso que la palabra tiene en $M F$, II, v. 414. Lo mismo ocurre con la acepción de "pataliar" (p. 1716); tal como se usa en $M F$, I, v. 1309 es equivalente a "estirar la pata". Debió agregar a la acepción que da de "ensartar" (p. 1701) la que tiene en $M F$, II, v. 3130: engañarse, caer en la trampa. Algo semejante ocurre con "boleta" (p. 1690) que en MF, II, v. 3371 equivale a voto.

16 En la edición de Battistessa de La cautiva, El matadero, 1a. ed. (Buenos Aires: Peuser, 1946; 2a. ed. 1958) figura en el "Apéndice", 
en el "Vocabulario". (que remite a una nota de la p. 80) por cuanto son diferentes.

11) De Juan María Gutiérrez Becco da los textos clásicamente aceptados como gauchescos: "A mi caballo", "Dos jinetes" y "Endecha del gaucho". Hemos advertido una errata en el primer poema, v. 62, p. 1636: debe decir más en vez de mas.

12) De Bartolomé Mitre compulsó la edición original y reproduce sus notas. Es singularmente interesante, para comprender cómo encaró Mitre estos poemas, la nota que puso al final de su Santos Vega porque explicita sus prejuicios acerca de la poesía gauchesca. Es nota de poca difusión pero cuyo conocimiento esclarece el criterio con que Mitre continuó en la senda abierta por Echeverría, aunque casi pudiera decirse que empezó la que sería toda una serie de 'proyecciones' del tema gaucho en lengua culta.

Las paesías de Mitre que Becco incluye son "Armonías de la pampa", "El pato. Cuadro de costumbres", "El caballo del gaucho". y "A Santos Vega, payador argentino". La nota de Mitre sobre el juego del pato pudo ser completada por Becco con la especificación de que aún se juega y en qué forma se lo ha modificado. Lo que resulta interesante en la nota de Mitre es su justificación de la acción dramática con que vitaliza lo que pudo ser una simple evocación descriptiva. Erratas: p. 1646, continuación de n. 39: foletinesca; $A I I I$ por A. III; p. 1657, nota, paso por pato.

13) Texto del Santos Vega de R. Obligado: En el C. II, 1ra. est., p. 1663 fa'ta el penúltimo verso "que un monótono murmullo", con lo cual se altera toda la numeración de los versos. Hemos anotado algunas discrepancias con el texto de Becco y el que trae Ricardo Lehmann-Nitsche en su libro Folklore argentino. Santos Vega, ${ }^{17}$ que sigue la $2 \mathrm{a}$. edición de las poesías de Obligado (Buenos Aires: 1906). Esas discrepancias son:

Becro:

C. III, v. 298: ese

C. IV, v. 504: en abismo

v. 523: que en mi espíritu bebía

\section{Lehmann:}

este

en el abismo que mi espíritu bebía

17 R. Lehmann-Nitsche, Folklore argentino. Santos Vega. Prólogo, biografía, bibliografía y notas por E. M. S. Danero (Buenos Aires: Helga S. LehmannNitsche de Mengel, 1962), pp. 32-48. Esta edición no aparece citada en la Bibliografta de Becco, p. 1752 . 
Puesto que R. Obligado consintió a esta transcripción de su poema por Lehmann, sería conveniente aclarar estas disparidades y fijar definitivamente el texto exacto de esos versos. Obligado, asimismo, anotó el texto para Lehmann y, por ejemplo, su nota a brillazón (C. I, v. 61) aclara su sentido de 'espejismo' que no se deduce fácilmente del texto. Becco no ha explicado esta voz. Creo, asimismo, que debió de explicar tristes del C. LV, v. 446, p. 1672. Errata: C. III, v. 321, p. 1669; vebre por vibre.

Pensamos que en esta selección de poesía gauchesca en lengua culta debió de aparecer el poema Láatro de Ricardo Gutiérrez, ${ }^{18}$ si no en su totalidad ( 3.000 versos en 4 cantos) por lo menos las famosas cinco décimas de la "Trova" del payador gaucho Lázaro. Comprendo las objeciones que pueden hacerse a esa obra: la estampa excesivamente byroniana de Lázaro (como lo reconoció desde el primer momento Pedro Goyena), la falsedad del ambiente colonial recreado, pero creo que el poema es importante en una visión histórica de la poesía gauchesca culta como la que la Antología de Becco nos da aun si se lo aprecia tan sólo como la saga de un héroe romántico víctima de la fatalidad y no según lo veía Goyena como un gaucho indignado contra "esa entidad odiosa llamada ayer mandatario de la corona española, y hoy juez de paz (...) Lázaro es el gaucho argentino, y R. Gutiérrez el primer poeta por cuyos libros se ha exhalado esa larga y triste queja de tres siglos", ${ }^{19}$ afirmaciones ambas que habria que someter a un más ajustado escrutinio sobre la base de un serio estudio del poema que aún está por hacerse. Poema, cuyo valor estético, aunque desparejo, no creo que pueda negarse por completo. Por lo demás, el mismo Becco lo menciona en nota 27, p. 23 de su edición de los Cielitos y Díalogos patrióticos de Hidalgo (Buenos Aires: Huemul, 1963) como uno de los autores cultos de poesía gauchesca junto a Magariños Cervantes y a Rafael Obligado. Asimismo, Borges y Bioy Casares en el "Prólogo" a su Poesía Gauchesca (pp. X-XI) suman su nombre a una lista en la que incluyen a Echeverría, M. Cervantes, Mitre y Obligado. $Y$ así en toda la crítica gauchesca tradicional. Hubiera sido, pues, especialmente útil esta inclusión teniendo en cuenta la inaccesibilidad de ese texto.

El volumen se cierra con dos instrumentos de gran utilidad para cualquier lector interesado que se acerque a él con la idea de obtener una información redondeada de ese fenómeno tan peculiar de las letras hispa-

18 Poesías escogidas (Buenos Aires, 1878). Hay reimpresión de 1882 con cambio de carátula. El poema se publicó inicialmente en 1869.

19 Revista Argentina (Buenos Aires, 1869), T. IV, pp. 298-354 apud. R. A, Arrieta, "La poesía de la generación del $80 "$ en Historia de la literatura argentina, T. III (Buenos Aires: Peuser, 1959), p. 297. 
noamericanas que es lo gauchesco. Me refiero al Vocabulario y a la Bibliografia. El primero contiene 2231 entradas (507 son nombres propios o de lugar). Allí se consignan todas las palabras $\longrightarrow$ nombres- anotadas en el texto, más aquéllas cuyo significado se considera necesario explicar porque se aparta del español general. Cuando la palabra aparece anotada en el texto se indica la página de la nota o se completa la significación allí dada, o también se agregan una o más significaciones. Es decir, que este "Vocabulario" actía como un diccionario de lengua gauchesca y, considerado el número de los textos que la Antología contiene, me atrevo a decir que es el primero y más completo de los repositorios de ese dialecto literario. Infortunadamente, es la parte del libro en que hemos encontrado más erratas en un volumen que, dado lo farragoso de su composición, se mantiene excepcionalmente limpio de ellas. Las indico al pie de esta nota pues como estoy segura de una segunda edición, deseo contribuir de este modo a aligerar la inevitable tarea de revisión.

La Bibliografía está organizada en tres secciones: "Bibliografía consultada" con 118 asientos; "La literatura gauchesca" - 533 asientos- y "Bibliografía complementaria" - 62 asientos - que fue agregada a última hora dada $l_{a}$ demora en la producción del volumen y que, en una próxima edición, se ordenará sistemáticamente en un solo cuerpo. Aunque Becco puntualiza que algunas de las obras consignadas se refieren a un solo tema, que otras son enfoques de conjunto sobre lexicografía o referencias históricas, geográficas y literarias y que se evitan las obras comunes y cercanas al ambiente literario de los poetas gauchescos que alargarian excesivamente la lista y que obligarian a compulsa de diarios y revistas imposibles de obtener a ambos lados del Atlántico, su bibliografía proporciona una selección fundamental y, si Becco no hubiera hecho la de José Hernández y $M F$ del volumen primero reseñado, este aporte sólo sería de consulta obligada para quien, seriamente, se acerque al estudio de la literatura gauchesca. De cualquier modo, él no se olvida de señalar el "riquísimo aporte" de la bibliografía de Cortázar publicada por el Fondo Nacional de las Artes.

El cuidado y detalle con que está hecha esta Bibliografía y la cantidad de sus asientos --713 en total - es demostrativa de la alta calidad del trabajo de Becco: no falta fecha de nacimiento (y muerte) del autor del trabajo (de ser accesible el dato), indicación de colección, primeras ediciones cuando el dato puede ser de valor, descripción del contenido, indicación de las páginas que contienen bibliografía y/o apéndices bibliográficos actualizados; de ilustradores, prologadores, etc. La sección más importante de esta Bibliografía es la titulada "La literatura gauchesca", dividida en tres partes: una dedicada a "El gaucho" ( 73 asientos) que 
abarca trabajos fundamentales y otros menores pero con cuya lectura puede obtenerse la definición, situación, principales rasgos y evolución del tipo y sus costumbres. Remite a la Bibliografía de Coluccio y a la "Bibliografía general" (que aparece al término de esta segunda parte y que es una bibliografía de bibliografías - 18 asientos-) para hallar las referencias históricas, etnográficas, folklóricas e iconográficas que Becco descarta aquí. La segunda parte es sobre "Literatura gauchesca" propiamente dicha (116 asientos) y proporciona lo indispensable y más serio de entre lo mucho escrito. Y la tercera parte es la "Bibliografía de los autores incluidos" (326 asientos) en que cada autor lleva una lista de sus "Obras" y otra de "Estudios críticos", con indicación de "Bibliografías especiales" cuando existen.

El volumen contiene, asimismo, una pequeña colección de "Ilustra. ciones", a media página. Son seis en total (cuatro litografías de Gregorio Ybarra y dos de Juan León Pallière) difundidas en la Argentina pero no así fuera de ese país y que han sido elegidas por Becco con un agudo sentido didáctico pues cubren seis aspectos visuales básicos para el que se interese por los gauchescos: el aspecto exterior y el interior de una pulpería con el especial interés de los tipos humanos, sus vestimentas, las mercancías; la carreta, la carrera; la riña de gallos y el payador en los que, al ya mencionado interés de la indumentaria y los seres, se agrega el del tinglado especial para las riñas y el de la china y el rancho del payador. Nítidamente reproducidas, agregan otra nota de calidad a este libro que tantas posee.

Erratas del "Vocabulario": Acevedo Díaz no aparece en p. 1141; agenciar: debe ser p. 702; aguarás: debe ser p. 1005, albuno: debe ser p. 1054; alunao: debe ser p. 994; anca: 3a. acep. debe ser p. 715; barcinos: debe ser p. 733 ; betún: debe ser p. 1052; bolas: 2a. acep. debe ser p. 722 ; cajetillas: debe ser p. 1045; calengo: debe ser p. 686; colita: no aparece en la p. 705; colorado: debe ser p. 765 , contra-moquillo: debe ser p. 960; corona: debe ser p. 1012; Corrales del Miserere: debe ser p. 821; corralitos por corralito; Cradoclo: debe ser p. 724; cuchillo: debe ser p. 779 (3a. acep.); chaná: debe ser p. 726; charabón: debe ser p. 1056; Chascomús: debe ser p. 731; chiflido: debe ser p. 709; choclo: 2a. acep., debe ser p. 694; choreo: debe ser p. 815; dar: Dar tres rayas: debe ser p. 728 ; dejuramente: debe ser p. 700 ; despiado: debe ser p. 965 ; diaónde: debe ser p. 699; Dorrego: debe ser p. 985; Dupotet: debe ser p. 730; duraznillo: no aparece en p. 177; Ejército Grande: debe ser p. 1041; enrabado: no trae significación o indicación de pág.; ensartar: la acepción que se da no se ajusta a la que aparece en $M F$; fiador: debe ser p. 1016; 
Flaco; 2a. vez debe ser p. 672; Fuerte, El: debe ser p. 989; gato: mis-mis dice p. 1965 no existente; Grenfell: debe ser p. 1028; Herrera y Obes: debe ser p. 1011; Homos: debe ser p. 686; Howden: debe ser p. 724; Juan de las Botas: debe ser p. 764; Juerza, La: debe ser p. 1029; Lagos debe ser p. 594, Lainé: debe ser p. 735; Lané: debe ser p. 596; larga 1ra. acep., debe ser p. 1008; Ler y: debe ser p. 739; loco: debe ser p. 1036; lomo: 1a. acep. debe ser p. 961; Macana: debe ser p. 696; macote: p. 729 inexacta; maestre: p. 675 inexacta; Mala-Cara: debe ser p. 734; manotect: debe ser p. 992; mansas: debe ser p. 734; maltreriar: debe ser p. 1013; matucho: debe ser p. 703; Maúa: debe ser p. 1059; mantas: p. 732 inexistente; mocho: debe ser p. 1015; Montiel: debe ser p. 1050; moquillo: p. 690 inexistente; De Moquillo: debe ser p. 689; morcilla: debe ser p. 1057; nación: debe ser p. 598; negao: debe ser p. 726; ñandu: debe ser p. 737; ñandubay: debe ser p. 1055; O'Reilly: p. 44 inexistente; Urganizador: debe ser p. 1050; pajarero: debe ser p. 696; palo, al palo: debe ser p. 738; pangaré: p. 704 inexistente; paro: debe ser p. 695; pedo, en pedo: debe ser p. 703; pelar el choclo: debe ser p. 694; Peña: debe ser p. 1011; Pérez, Pablo: p. 431 inexístente; picana, pelar la: debe ser p. 742; plata: bablar en: debe ser p. 727; Poblaciones, Conde de: debe ser p. 742; Purvis: debe ser p. 719; quebrallón: debe ser p. 688 y p. 1022; quincha: debe ser p. 968; redomonear: debe ser p. 1012; Residencia, La: debe ser p. 750; rifa: sin explicación o indicación de pág.; Rincón de Ajó: debe ser p. 731; Rodriguez, Camilo: debe ser p. 766; Sacrá: debe ser p. 1017; Santander: debe ser p. 686; Sepeduro: debe ser p. 1031; silla, en silla: debe ser p. 1056; tabuneros: debe ser p. 1051; tala: debe ser p. 1055; tallar al monte: debe ser p. 1009; Taqueño por taqueño (p. 1724); trajinar: debe ser p. 974; venado: debe ser p. 1016; vicios, los: debe ser p. 700; Vidal, Emilio: sin indicación de pág.; yaguaná por yaguané; zurda: debe ser p. 980.

Angela B. Dellepiane

City College \& Graduate

Center - CUNY 